\title{
Temporal Evolution of Coherent Precipitates in an Aluminum Alloy W319: A Correlative Anisotropic Small Angle X-Ray Scattering, Transmission Electron Microscopy and Atom-Probe Tomography Study
}

\author{
Aniruddha Biswas, ${ }^{1,4}$ Debasis Sen, ${ }^{2}$ Sudip Kumar Sarkar, ${ }^{1}$ Sarita, ${ }^{1}$ S. Mazumder, ${ }^{2}$ and David N. \\ Seidman 3,4 \\ ${ }^{1}$ Glass and Advanced Materials Division, ${ }^{2}$ Solid State Physics Division, Bhabha Atomic \\ Research Centre, Mumbai-400085, India \\ ${ }^{3}$ Department of Materials Science and Engineering, Northwestern University \\ 2220 Campus Drive, Evanston, IL 60208, USA \\ ${ }^{4}$ Northwestern University Center for Atom-Probe Tomography (NUCAPT), Evanston, IL 60208, \\ USA
}

\begin{abstract}
Small-angle X-ray scattering (SAXS), transmission electron-microscopy (TEM), and atom-probe tomography (APT) are utilized correlatively to study the evolution of nanometer length-scale coherent precipitates in a commercial age-hardenable aluminum alloy, W319. SAXS, with its high-field-of-view and resultant large statistics, perfectly complements TEM and APT at the nanometer length-scale. The combined results provide a comprehensive description of the evolution of the fine precipitates. W319 exhibits two types of fine coherent precipitates on aging namely, $\theta^{\prime}$ and $\mathrm{Q}$, whose temporal evolution has been studied using time-resolved in situ SAXS analyses at three different aging temperatures: 438, 463, and $533 \mathrm{~K}$. Complementary information about the morphology, dimensions and number density of the precipitates were determined from ex situ APT and TEM analyses. Coherent precipitates from a single grain of the $\alpha$-Al-matrix of W319 give rise to an anisotropic SAXS signal, which is subsequently simulated, taking into account the relative orientation of the sample and the crystallographic orientation relationships of the different precipitates. The simulated anisotropic SAXS intensity, based on the results from APT and TEM, is validated utilizing the experimentally obtained 2D SAXS patterns. This permits us to determine the dimensions and number densities of the precipitates from anisotropic SAXS signals, and a complete quantitative analysis of the in situ temporal evolution of the coherent precipitates is performed. Additionally, the present study demonstrates an alternative technique for extracting structural parameters from anisotropic SAXS analyses. The methodology presented herein will be useful for age-hardening analyses of commercial agehardenable Al-based alloys and Ni-based super alloys.
\end{abstract}

Key words: Small-angle X-ray scattering (SAXS), atom-probe tomography (APT), $\theta^{\prime}-$ precipitates, Q-phase precipitates, aluminum alloy W319 


\section{Introduction}

Age-hardenable Al-alloys, a popular choice for a wide range of commercial applications, owing to their strength, which is mainly due to the presence of different nanometer length-scale coherent precipitates. W319 is one such alloy, which finds extensive use in the automobile industry [1-2] and two types of coherent nanometer length-scale precipitates, namely $\theta^{\prime}$ and $\mathrm{Q}$ [3], are well known to be important in this alloy. This high-Si concentration heat-treatable cast alloy contains at least six different elements, with $\mathrm{Cu}$ being the other dominant element after $\mathrm{Si}$ [3-4]. Excess Si concentrations in W319 improve its castability because it adds fluidity to the melt [4].

Differential scanning calorimetry (DSC) analyses have demonstrated that Q-phase precipitation precedes $\theta^{\prime}$-precipitation in W319 [3], as in the case of 2014 Al-matrix composites [5]. The precipitation sequence in $\mathrm{W} 319$ is as follows: GP zones $\rightarrow \mathrm{Q} \rightarrow \mathrm{Q}+\theta^{\prime}$ [3]. As for Al$\mathrm{Cu}$ binary alloys, ordered metastable $\theta^{\prime}$-phase imparts the maximum strengthening effect of any phase in this precipitation sequence in W319 [6-7]. Given its importance for strengthening Al alloys, a large number of studies have focused on the properties of metastable $\theta^{\prime}$-precipitates [811]. Thus, determining the kinetics of precipitation in these Al alloys is crucial for making quantitative correlations with their strength.

The $\theta^{\prime}$-phase possesses a body-centered-tetragonal crystal structure with the stoichiometry $\mathrm{Al}_{2} \mathrm{Cu}$, while on the mesoscopic length scale, $\theta^{\prime}$-precipitates have a high-aspectratio platelet morphology with coherent $(001) \theta^{\prime} \|\{001\} \alpha$-Al interfaces parallel to their broad faces and semi-coherent interfaces at their peripheries [8]. This orientation relationship, where the $c$ axis of the tetragonal precipitate aligns along the cube axes of the $\alpha$-Al (f.c.c.) matrix, gives rise to three orientation variants. The platelet morphology of $\theta^{\prime}$-precipitates is often rationalized by a large anisotropy in the interfacial Gibbs free $(\sigma)$ and elastic-strain energies between the coherent and semi-coherent interfaces, with the broad coherent interfaces possessing a smaller $\sigma$ value than the semi-coherent interfaces [6,9-11]. The dimensions of $\theta^{\prime}$-precipitates are known to vary with alloy composition, processing history and aging conditions. In the case of W319 for a T6 aging treatment, they are typically in the range 50 to $100 \mathrm{~nm}$ diam. and $<10 \mathrm{~nm}$ thick [7]. The aspect ratio of $\theta^{\prime}$-precipitates, at times, may, however, be as large as 40 [11].

TEM has been widely used for analyzing $\theta^{\prime}$-precipitates and its temporal evolution, including its growth and coarsening kinetics [12-15]. Precipitate dimensions are normally determined in the edge-on orientation and often a large number of precipitates are measured to obtain good statistics [7, 13]. Relatively little is known, however, concerning the compositional evolution of $\theta^{\prime}$-precipitates since its nanometer length-scale platelet-like morphology makes 
quantitative analytical TEM analyses extremely difficult. An alternative to TEM is modern atomprobe tomography (APT), which is immune to these problems, and is currently the most suitable technique at the subnano-to-nanometer length-scale for studying the composition of fine precipitates. But, there have been relatively few APT studies on the temporal evolution of $\theta^{\prime}$ precipitates, with the majority of the studies focusing on precipitate nucleation [16-17]. Shollock et al. [18] and Sano et al. [19] performed APT analyses of $\theta^{\prime}$-precipitates in Al-1.7Cu-0.34Mg$0.1 \mathrm{Ag}$ at. $\%$ and $\mathrm{Al}-2.7 \mathrm{Cu}-0.5 \mathrm{Mg}-0.1 \mathrm{Ag}-0.26 \mathrm{Mn}-0.04 \mathrm{Zr}$ at. $\%$ alloys, respectively, and reported two different $\mathrm{Cu}$ concentrations for the $\theta^{\prime}$-phase. Shollock et al. [18] obtained an $\mathrm{Al}_{3} \mathrm{Cu}$ stoichiometry for the $\theta^{\prime}$-phase, whereas Sano et al. [19] found a stoichiometry of $\mathrm{Al}_{2} \mathrm{Cu}$. Recently, we have employed APT to study both compositional evolution and interfacial segregation of $\theta^{\prime}$-precipitates in Al-Cu alloys and W319 [20-21].

An Al-Mg-Si-Cu-based quaternary or "Q-phase" is the second type of nanometer-scale precipitate commonly present in W319. The earliest reference to Q-phase is by Dix et al. [22]. The Q-phase is generally known to have a hexagonal crystal structure with lattice constants $a=$ 10.35-10.40 $\AA, c=4.02-4.05 \AA[23-25]$. The related $\mathrm{Q}^{\prime}$-phase is a coherent or semi-coherent version of the Q-phase having essentially the same crystal structure with slightly different lattice parameters [23, 25-27].

Q-phase precipitates usually exhibit a lath or needle-like morphology [7]. Typical dimensions of Q-phase precipitates, depending upon the aging conditions, are in the range 2.0 to $5.0 \mathrm{~nm}^{2}$ in cross-section and 60 to $100 \mathrm{~nm}$ in length [28]. The long axis of these precipitates is known to be parallel to $\left\langle 100>_{\alpha-\mathrm{Al}}\right.$, and the generally accepted habit plane is $\{150\}_{\alpha-\mathrm{Al}}[27-28]$. Details of some of the earlier research on this phase are in articles by Weatherly et al. [23] and Chakrabarti et al. [27].

The composition of Q-phase precipitates is debatable, as noted previously [23, 25, 27]. Only a few experimental studies of Q-phase precipitates have been reported, based mainly on TEM-EDS analyses [29-31]. Hwang et al. [32] used APT analysis and reported the composition of the $\mathrm{Q}^{\prime}$-phase precipitates for the T6 aging condition in a 319-type Al-alloy to be $\mathrm{Al}_{4} \mathrm{Cu}_{2} \mathrm{Mg}_{8} \mathrm{Si}_{7}$. More recently, we have explored the compositional evolution of Q-phase precipitates in W319 using local-electrode atom-probe (LEAP) tomography, differential scanning calorimetry (DSC), X-ray diffraction, TEM, and first-principles calculations [3].

Today, modern APTs are widely accepted to be an indispensable instrument for quantitative analyses of nanometer-scale phenomena, e.g., precipitation in age-hardenable Alalloys. The maximum field-of-view (FOV) of an APT is currently 200x200 $\mathrm{nm}^{2}$, which limits the statistics of APT analysis in some cases. In contrast, the SAXS technique offers a large FOV, resulting in excellent statistics at the same length-scale. Therefore, SAXS is effective for quantitative analyses of the dimensions and volume fraction of fine clusters and precipitates in a 
metallic matrix. SAXS has been applied extensively to a wide variety of age-hardenable Alalloys for precipitation analyses [33-37]. This technique has been popular for studying precipitation mechanisms in metallic systems based on the pioneering research of Guinier [3839]. As explained by Simon [40], it is difficult to estimate accurately the Porod invariant solely from SAXS measurements. This is because it cannot provide independently both the compositions and volume fractions, because they are linked by the integrated intensity. Under these circumstances, independent APT analyses provide a way to ameliorate this situation [4041]. Additionally, SAXS as a technique, unlike APT, is amenable to in situ time-resolved analyses of precipitation processes [42]. Therefore, these two techniques complement and supplement one another and their combination plus TEM can provide a more complete and quantitative description of the temporal evolution of small precipitates [40-41, 43].

The current article illustrates the excellent complementary capabilities of these analytical techniques; it combines the results of 3D-APTand TEM analyses of the evolution of $\theta^{\prime}$ - and Qphase precipitates in W319, with SAXS results from the same alloy. Additionally, this research presents time-resolved in situ SAXS experiments of solutionized W319 samples at three different aging temperatures, using a 2D position-sensitive detector. It is emphasized, however, that the coherent precipitates are often non-spherical and are always associated with certain crystallographic habit planes, and therefore a small-angle scattering (SAS) signal from a single crystal or a textured polycrystalline sample is by its nature anisotropic. In such cases, as demonstrated by Fratzl and co-workers [44-45], a 2D detector becomes especially useful and the more popular practice of radially averaging the SAS signal is no longer adequate. Fratzl et al. [44-45] developed a method for quantitative interpretation of the intensity streaks observed in SAS experiments. Their method is, however, reportedly suited more for precipitates with a moderate aspect ratio [46]. Recently, De Geuser et al. [46] presented another procedure for determining the morphology, volume fraction and number density of $\theta^{\prime}$ and the so-called $\mathrm{T}_{1}$ precipitates in the Al-Li-Cu system from similar anisotropic SAS signals. In the present research, coherent precipitates from a single grain of the $\alpha$-Al (f.c.c.) matrix of W319 give rise to an anisotropic SAXS signal, which is matched with its simulated intensity. Anisotropic intensity simulations have been performed by employing a similar procedure, De Geuser et al. [46], which uses the habit plane information of the respective precipitates. Essential complimentary and correlative information about the morphology, dimensions, and number density of precipitates was extracted utilizing 3D-APT and TEM analysis.

\section{Methodologies}

\subsection{Experimental methods}


Ford Motor Company (Dearborn, Michigan) provided samples of the commercial W319 alloy. This 319-type alloy differs in composition from the Aluminum Association 319 composition in terms of the $\mathrm{Si}, \mathrm{Fe}, \mathrm{Mg}$, and $\mathrm{Mn}$ specified concentration limits [47]. Detailed bulk chemical compositions of this alloy are given in Ref. [3]. Samples were homogenized in air at $758 \mathrm{~K}$ for $24 \mathrm{~h}$, followed by water quenching, and then aged in air at 433, 463, and $533 \mathrm{~K}$ for 8,8 , and $4 \mathrm{~h}$, respectively. The rationale behind choosing the aging conditions is discussed in our earlier article [3]. We do not make a distinction between the $\mathrm{Q}$ - and $\mathrm{Q}^{\prime}$-phase precipitates and refer to them collectively as Q-phase precipitates, because the difference between their structures and compositions are insignificant.

Specimens for TEM were prepared by punching out discs with a $3 \mathrm{~mm}$ diam. from thin foils with a thickness of $\sim 200 \mu \mathrm{m}$, followed by grinding with 600 -grit SiC paper to a thickness of $70 \mu \mathrm{m}$, dimpling, and ion milling using a Gatan precision ion-polishing system (PIPS). TEM was performed employing a JEOL 2000FX microscope at $200 \mathrm{kV}$. Bright-field images were obtained with the foils oriented slightly off the $\left\langle 100>_{\alpha}\right.$-Al zone axis to optimize the contrast between the matrix and the precipitates.

Site-specific dual-beam focused-ion beam (FIB) milling was utilized to prepare APT specimens [48-54], as electropolishing is ineffective for W319 [3]. A dual-beam FEI Helios FIB microscope, in combination with an Omniprobe micromanipulator, was used for the lift-out procedure [3].

APT was performed utilizing the ultraviolet (UV) laser-pulsing mode employing LEAP tomography (Cameca, Madison, WI) [55-60] in the Northwestern University Center for AtomProbe Tomography (NUCAPT). The specimen temperature was maintained at $40 \pm 0.3 \mathrm{~K}$. The ultraviolet (wavelength $=355 \mathrm{~nm}$ ) picosecond laser pulse energy was $0.7 \mathrm{~nJ}$ pulse $\mathrm{s}^{-1}$ and the pulse repetition rate was $500 \mathrm{kHz}$. The LEAP tomographic data were analyzed employing the program IVAS 3.0 (Cameca). The parameters used for the isoconcentration surfaces are: voxel size = $1 \times 1 \times 1 \mathrm{~nm}^{3}$, delocalization distance $=3 \mathrm{~nm}$, and a sample count threshold $=1 \%$. Efficient sampling procedures [61] were used to generate these isoconcentration surfaces and the compositional information was obtained with the proximity histogram method [62]. All error bars presented correspond to two standard deviations from the mean for the compositional analyses. Additional details concerning experimental and analysis procedures are given in Ref. [63-68].

Scattering experiments were performed using a laboratory-based SAXS instrument equipped with a $2 \mathrm{D}$ position sensitive detector. The sample to detector distance was $\sim 1 \mathrm{~m}$. Diameter of the x-ray beam incident on the sample was $400 \mu \mathrm{m}$. For in situ experiments, a thinned alloy sample $(\sim 100 \mu \mathrm{m})$ was placed in a sample heating stage at $10^{-2}$ Torr at 438,463 or 
$533 \mathrm{~K}$ for the following different aging times: 24,8 and $4.67 \mathrm{~h}$, respectively. Experimental profiles were recorded as a function of aging time, while maintaining the sample at a constant temperature.

\subsection{Modeling anisotropic SAXS pattern}

At this point we first discuss the methodology [46] to simulate the anisotropic 2D SAXS pattern that originates from the oriented cylindrically-shaped precipitates. Let us first concentrate on a single cylinder of radius $R$ and height $h$. We consider a Cartesian coordinate system $(x, y, z)$, where the $z$-direction coincides with the long axis of the cylinder and $x$ and $y$ lie on the crosssectional plane of the cylinder. We define the wave vector transfer, $\boldsymbol{q}$, with components along the $x, y$ and $z$ directions as $q_{x}, q_{y}$ and $q_{z}$, respectively. The small-angle scattered intensity from the cylinder is given by:

$$
I\left(q_{x}, q_{y}, q_{z}\right)=\Delta \rho^{2} V^{2}\left|\frac{\sin \left(q_{z} h / 2\right)}{\left(q_{z} h / 2\right)}\right|^{2}\left|\frac{2 J_{1}\left(q_{R} R / 2\right)}{\left(q_{R} R / 2\right)}\right|^{2}
$$

where $J_{l}$ is the Bessel function of the first kind, $\Delta \rho$ is the difference in the electronic (or scattering length) density between the matrix and precipitates, $q_{R}=\left(q_{x}{ }^{2}+q_{y}{ }^{2}\right)^{1 / 2}, V$ is the volume $\left(\pi R^{2} h\right)$ of the cylindrical precipitate.

Direct space and reciprocal space are related by a Fourier transform, for a cylinder with $h$ $<<$ (i.e., plate-like object) the SAS signal extends more in the $q_{z}$-direction. When the aspect ratio is high this effect is enhanced, and therefore the extension of the intensity along the $q_{z^{-}}$ direction becomes significantly greater than along the other direction on the $2 \mathrm{D}$ detector, giving rise to a streaking effect. In case of polycrystalline or powder samples (sample has a random texture with a grain size much smaller than the beam size), an angular dispersion of cylinder orientations will give rise to an isotropic signal on a $2 \mathrm{D}$ detector because of orientational averaging. We now consider the intensity scattered on the $2 \mathrm{D}$ detector at a point $P\left(p_{x}, p_{y}, p_{z}\right)$. If $L$ is the distance between the sample and the center of the $2 \mathrm{D}$ detector then the following equations are obtained:

$$
\begin{aligned}
& q_{x}=k \sin \left[(1 / 2) \tan ^{-1}\left(p_{x} / L\right)\right] \\
& q_{y}=-k \sin 2\left[(1 / 2) \tan ^{-1}\left\{\frac{\left(p_{x}^{2}+p_{z}^{2}\right)^{0.5}}{L}\right\}\right] \\
& q_{z}=k \sin \left[(1 / 2) \tan ^{-1}\left(p_{z} / L\right)\right]
\end{aligned}
$$


Initially, we take the axis of the cylinder to coincide with the direction of $\boldsymbol{q}$. Assuming a distribution of cylinder lengths and radii, the scattered intensity is given by:

$$
\begin{aligned}
& I=N_{v} \Delta \rho^{2} I_{I} I_{2} \\
& \text { where } I_{1}=\sum_{i} \pi^{2} h_{i}^{2} D_{h}\left(h_{i}, h_{m}, \sigma_{m}^{h}\right)\left(\frac{\sin \left(\frac{q_{z} h_{i}}{2}\right)}{\left(\frac{q_{z} h_{i}}{2}\right)}\right)^{2}
\end{aligned}
$$

and

$$
I_{2}=\sum_{i} R_{i}^{4} D_{R}\left(R_{i}, R_{m}, S_{m}^{R}\right)\left(\frac{J_{l}\left(\frac{q_{R} R_{i}}{2}\right)}{\left(\frac{q_{R} R_{i}}{2}\right)}\right)^{2}
$$

If the axes of the cylindrical precipitates aren't aligned perfectly along the direction of $\boldsymbol{q}$, then a rotational matrix can be introduced to take into account the rotation, either in-plane or outof-plane. For an in-plane rotation:

$$
q_{x}^{\prime}=q_{x} \cos (\phi)-q_{z} \sin (\phi), q_{y}^{\prime}=q_{y} \text { and } q_{z}^{\prime}=q_{x} \sin (\phi)+q_{z} \cos (\phi)
$$

and for an out-of-plane rotation:

$$
q_{y}^{\prime}=q_{y} \cos (\phi)-q_{z} \sin (\phi), q_{x}^{\prime}=q_{x} \text { and } q_{z}^{\prime}=q_{y} \sin (\phi)+q_{z} \cos (\phi)
$$

\section{Results}

\subsection{Microstructure of W319: transmission electron microscope analyses}

In the as-solutionized condition W319 has a multiple-phase dendritic microstructure with an $\alpha$-Al matrix containing eutectic $\mathrm{Si}$, an intermetallic phase commonly known as the Script phase, and porosity $[3,7]$. The $\theta^{\prime}$ - and Q-phase precipitates emerge upon aging, as displayed in the representative aged microstructures corresponding to $8 \mathrm{~h}$ at $438 \mathrm{~K}$ (Fig. 1a) and $4 \mathrm{~h}$ at $533 \mathrm{~K}$ 
(Fig. 1b), respectively. The inset in Fig. 1a displays a magnified view of the precipitates as indicated by arrows. The bright-field micrographs are obtained from the $\langle 100\rangle_{\alpha \text {-Al-zone and the }}$ corresponding diffraction pattern is given in the inset, Fig. 1b. The diffraction pattern depicts a combination of reflections from $\alpha$-Al (f.c.c.) along with different variants of $\theta^{\prime}$ - and Q-phase precipitates [5, 32]. Both $\theta^{\prime}$ - and Q-phase precipitates are observed for the three aging conditions. No GP-zones were detected in any of the aged samples. The $\theta^{\prime}$-precipitates are

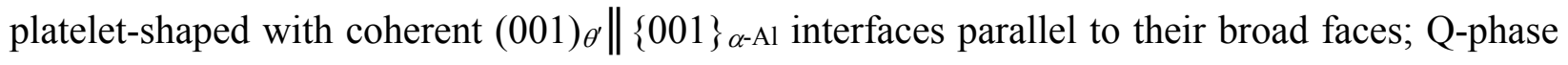
precipitates exhibit needle- or rod-like morphologies, with their long-axis parallel to $\langle 100\rangle_{\alpha-\mathrm{Al}}$. With increasing aging temperature the precipitate dimensions increase and concomitantly the number density decreases, which is indicative of coarsening (Ostwald ripening). The average dimensions of the $\theta^{\prime}$-precipitates and their number densities corresponding to each aging condition are determined utilizing TEM micrographs, Table 1. The same could not, however, be achieved for the Q-phase precipitates because of the length-scale involved. APT analyses are more appropriate for the Q-phase precipitates as demonstrated in the next sub-section.

\subsection{APT analyses: 3D nanostructure and composition}

As anticipated from the TEM results, platelet-shaped $\theta^{\prime}$-precipitates and thin rod-shaped Q-phase precipitates are observed utilizing APT analyses of all the aged W319 samples. The lower aging temperatures, 438 and $463 \mathrm{~K}$, present very similar results. Fig. 2a displays a typical $3 \mathrm{D}$ reconstruction of an analyzed volume containing $\sim 16 \times 10^{6}$ atoms, from a sample aged for $8 \mathrm{~h}$ at $463 \mathrm{~K}$; only $\mathrm{Al}$ (blue), $\mathrm{Cu}$ (red) and $\mathrm{Mg}$ (green) atoms are displayed for clarity. Fig. 2b displays a selected portion of the same dataset, where the $\theta^{\prime}$ - and the Q-phase precipitates are delineated by $\mathrm{Cu}$ and $\mathrm{Mg}$ isoconcentration surfaces, respectively. Fig. $2 \mathrm{~b}$ establishes clearly the typical expected morphologies specific to each type of precipitate. Fig. 2a-b also highlight the fact that the $\theta^{\prime}$-precipitates have a higher $\mathrm{Cu}$ concentration, whereas the Q-phase precipitates are relatively richer in $\mathrm{Mg}$. Fig. 2c displays another 3D reconstruction corresponding to aging at 533 $\mathrm{K}$ for $4 \mathrm{~h}$, which contains one solitary $\theta^{\prime}$-precipitate in its analysis volume. This is not surprising because a higher aging temperature leads to larger dimensions and concomitantly smaller number densities of precipitates; these results agree with the TEM results, Fig. $1 b$.

The proximity histogram (proxigram for short) methodology [61-62] was used to analyze the composition of the precipitates as a function of distance normal to the particular isoconcentration surface chosen to delineate them. Fig. 3 illustrates one example where this methodology was applied to determine the composition of a $\theta^{\prime}$-precipitate using a 9 at. $\% \mathrm{Cu}$ isoconcentration surface. The solid vertical line indicates the location of the heterophase interface between the $\alpha$-Al-matrix and the precipitate, which is, by definition, at the inflection 
point of the $\mathrm{Al}$ concentration-profile. The spatial concentration profiles of the precipitate and the $\alpha$-Al-matrix are displayed on the right- and left-hand-sides of this vertical line, respectively. Although richer in $\mathrm{Cu}$ at lower aging temperatures, $\theta^{\prime}$-precipitates display a composition very close to ca. $\mathrm{Al}_{2} \mathrm{Cu}$ on aging at $533 \mathrm{~K}$ for $4 \mathrm{~h}$. Table 1, along with the dimensions and number densities, displays the evolution of the compositions of the $\theta^{\prime}$-precipitates with increasing aging temperatures. With respect to the compositional evolution of the Q-phase precipitates (Table 2), aging at the lower two temperatures, 438 and $463 \mathrm{~K}$, yields Q-phase precipitates that are $\mathrm{Cu}$-rich and $\mathrm{Mg}$ and Si poor, with an overall composition of approximately $44 \mathrm{Al}-22 \mathrm{Cu}-16 \mathrm{Mg}-16.5 \mathrm{Si}$ at. $\%$ [3]. The composition of the Q-phase precipitates becomes Mg- and Si-rich after aging at 533 $\mathrm{K}$ for $4 \mathrm{~h}$ : $\sim 28 \mathrm{Al}-9 \mathrm{Cu}-37 \mathrm{Mg}-26 \mathrm{Si}$ at. $\%$. Additionally, APT provides evidence for partitioning of $\mathrm{Zn}$ to the Q-phase precipitates. The $\mathrm{Zn}$ concentration in the Q-phase precipitates decreases with increasing aging temperature, from $1.08 \pm 0.44$ at. $\% \mathrm{Zn}$ after aging at $438 \mathrm{~K}$, to $\sim 750$ at. ppm $\mathrm{Zn}$ after aging at $533 \mathrm{~K}$. The average dimensions and the number densities of the Q-phase precipitates for each aging condition are determined from the APT analyses, Table 2.

\subsection{SAXS analysis}

\subsubsection{SAXS analysis for ex situ experiments}

Fig. 4a-c displays the experimentally obtained ex situ SAXS pattern corresponding to the following three aging conditions: $438 \mathrm{~K}$ for $8 \mathrm{~h}$ (Fig. 4a); $463 \mathrm{~K}$ for $8 \mathrm{~h}$ (Fig. 4b); and $533 \mathrm{~K}$ for $4 \mathrm{~h}$ (Fig. 4c). The grain size (typically $>500 \mu \mathrm{m}$ [69]) of the $\alpha$-Al (f.c.c.)-matrix is larger than the incident $\mathrm{x}$-ray beam diameter, which ensures an effectively single-crystalline anisotropic scattering intensity; characteristic streaking is observed for each aging condition [44]. The sample plane in each case makes, however, certain random angles both in-plane and out-of-plane with respect to the incident beam, which results in asymmetric streaking and unequal streak lengths [46]. As the first step towards simulating this anisotropic intensity, all the variants of the $\theta^{\prime}$ - and Q-phase precipitates [70] are listed along with their relative angular relationships, Table 3 ; (i) assuming the incident $\mathrm{x}$-ray beam is parallel to $\langle 100\rangle_{\alpha \text {-Al; }}$; and (ii) without considering any out-of-plane deviation. Based on this, we have simulated the SAS intensities of two coherent precipitates present in a single grain of the $\alpha$-Al (f.c.c.)-matrix. Fig. 5a-c displays the simulated 2D scattering patterns corresponding to aging at $463 \mathrm{~K}$ for $8 \mathrm{~h}$ for the following three cases: (i) only two variants of $\theta^{\prime}$-precipitates are considered independently (Fig. 5a); (ii) four variants of the Q-phase precipitates are considered independently (Fig. 5b); and (iii) a combination of all six variants (Fig. 5c). All the relevant data, including the experimentally obtained values of the linear dimensions and number densities of the precipitates, which are used for this simulation, 
are listed in the bottom portion of Table 3. It is evident from Table 3 that the scaling factor is 40,000 times in favor of the $\theta^{\prime}$-precipitates and Fig. 5c demonstrates that point. The total volume of $\theta^{\prime}$-precipitates clearly outweighs the contribution of the number density, as far as the relative scattering length density is concerned. In the next stage of the simulation, the unequal streak lengths observed in the experiments have been modeled using an additional out-of-plane tilt, De Geuser et al. [46]. In the present case, an out-of-plane tilt angle of $8^{0}$ accounts successfully for the unequal streak lengths, as displayed in Fig. 6a-c, corresponding to the ex situ SAXS analysis of the sample aged at $463 \mathrm{~K}$ for $8 \mathrm{~h}$. Figs. 6a and b display the experimental and simulated results, respectively. Fig. $6 \mathrm{c}$ depicts the overlap of simulated and experimental scattering patterns one-on-top-of-the-other. The contour map in Fig. 6c confirms that the simulated image resembles the experimental scattering pattern very well.

\subsubsection{SAXS analysis for in situ experiments}

At the outset the in situ SAXS analysis focuses solely on the evolution of the $\theta^{\prime}$ precipitates, since the small relative scattering contrast of the Q-phase precipitates (Table 3, Fig. 5c) makes them virtually imperceptible in our in situ SAXS experiments. Fig. 7 displays representative temporal evolution patterns of the SAXS intensity corresponding to in situ analyses of W319 at $463 \mathrm{~K}$. To extract size information of the $\theta^{\prime}$-precipitates from the streaks obtained in the in situ SAXS experiments, a line was drawn along the experimental streak and the intensity variation was measured along that line. The thickness and radius values were then recorded on the basis of the maximum achievable matching condition between the experimental and simulated patterns. The error associated with a parameter was estimated by varying that particular parameter until the onset of a perceptible deviation between the simulated and experimental patterns occurred, while maintaining the other parameters fixed. Simulation of the in situ SAXS patterns was scaled in terms of the available ex situ experimental data [46]. We performed this image analysis exercise, both for the experimental patterns as well as for the simulated patterns, using the freeware program Image-J (http://imagej.nih.gov/ij/download.html). Fig. 8 depicts a typical comparison of the intensity variation along a streak between the experimental and simulated patterns, for a specimen aged in situ for $8 \mathrm{~h}$ at $463 \mathrm{~K}$. As anticipated, the intensity of the streak has a maximum value in its middle and it gradually decreases with increasing scattering angle. We note that because of the presence of a beam stop (which protects the detector from the direct beam), the intensity falls sharply around the beam's center. A similar procedure was performed for comparing each experimental pattern and its corresponding simulated pattern of the in situ SAXS experiments; 20 different time intervals were employed for aging at 533 and $463 \mathrm{~K}$, and 50 time intervals for aging at $438 \mathrm{~K}$. Figs. 9a and b display the 
temporal variations of thickness and radius of the $\theta^{\prime}$-precipitates, respectively, for all the samples aged at 438 (up to $24 \mathrm{~h}$ ), 463 (up to $8 \mathrm{~h}$ ) and 533K (up to $4.67 \mathrm{~h}$ ). As anticipated, the thickness of the $\theta^{\prime}$-precipitates exhibits only marginal growth with increasing aging time. For example, for aging at $438 \mathrm{~K}$, the thickness achieves a value of $4.3 \mathrm{~nm}$ after aging for $23.8 \mathrm{~h}$, as compared to a value of $2.5 \mathrm{~nm}$ after $6.95 \mathrm{~h}$. The results we obtained are similar for the other two aging temperatures. Higher aging temperatures lead to larger values of thicknesses for the same aging conditions. Alternatively, the radii of the $\theta^{\prime}$-precipitates increase steadily with increasing aging time for the three aging temperatures. For example, for aging at $463 \mathrm{~K}$, the radius of the $\theta^{\prime}-$ precipitates after aging for $8 \mathrm{~h}$ is essentially double its value recorded after $0.33 \mathrm{~h}$. Thus, increasing the aging temperature results in $\theta^{\prime}$-precipitates of progressively larger radii. Additionally, temporal exponent for the mean radius, $\langle R(t)>$, corresponding to each aging temperature was determined using a multivariate nonlinear regression analysis [71], Fig. 9b. We note that the radius of the $\theta^{\prime}$-precipitates could not be calculated for less than an aging time of $6.95 \mathrm{~h}$ for the lowest aging temperature, $438 \mathrm{~K}$, due to the absence of a sufficiently strong scattering signal.

From the thickness and radius values of the $\theta^{\prime}$-precipitates their volume was determined. The total integrated intensity of the $2 \mathrm{D}$ image was also calculated. This integrated intensity depends on the product $N_{v} \Delta \rho^{2} v^{2}$. As the scattering contrast $\left(\Delta \rho^{2}\right)$ between the precipitates and the matrix and also the volume of the precipitates $(v)$ are known, the variation of the number density $\left(N_{v}\right)$ may be estimated from the variation of $N_{v} \Delta \rho^{2} v^{2}$. Thus, the temporal variation of $N_{v}$ was extracted by dividing the integrated intensity by $\Delta \rho^{2} v^{2}$, and by proper scaling of $N_{v}$ at the same level that was obtained from the APT data for an individual sample. The variation of $N_{v}$ with aging time, as calculated by the above procedure, is plotted in Fig. 10, which compares the aging responses at 463 and $533 \mathrm{~K}$. The number density plot corresponding to aging at $438 \mathrm{~K}$ is similar to that of $463 \mathrm{~K}$ and hence it is not included in Fig. 10. The inset in Fig. 10 displays a magnified view of the plot for aging at $533 \mathrm{~K}$, highlighting the same parabolic nature, as exhibited by the plot for aging at $463 \mathrm{~K}$. As anticipated, the lower aging temperature displays a much higher value $\left(\sim 10^{23} / \mathrm{m}^{3}\right)$ of the peak number density of $\theta^{\prime}$-precipitates, and this result is consistent with our TEM and APT results. At a higher aging temperature, $N_{v}$ achieves its peak value significantly more rapidly than at the lower aging temperature. For example, it takes only $0.5 \mathrm{~h}$ at $533 \mathrm{~K}$ to reach the maximum value of $N_{v}$, as opposed to $2 \mathrm{~h}$ at $463 \mathrm{~K}$. Temporal exponents for the number density, $N_{v}$ of precipitates were determined using a multivariate nonlinear regression analysis [71], which are displayed in Fig. 10. Once again, we emphasize that the information about $N_{v}$ cannot be extracted below a certain threshold time interval due to a weak scattering signal. As a result, we have assumed the initial number density to be zero and 
interpolated the initial few values based on the trend obtained from our scattering results. The interpolated values are marked in Fig. 10 and its inset.

\section{Discussion}

We combine anisotropic single-crystal SAXS with TEM and APT, and present in-depth quantitative analyses of the temporal evolution of nanometer length-scale coherent precipitates; namely, $\theta^{\prime}$ - and Q-phase precipitates in the high-Si commercial Al-alloy W319. As for the $\theta^{\prime}$ precipitates, its dimensions have been determined using TEM results of the aged samples (Table 1), which agree with archival literature values [7]. Alternatively, information about the morphology and dimensions of the relatively smaller Q-phase precipitates are successfully obtained utilizing APT analyses, Table 2. Also in this case, the dimensions of the Q-phase precipitates we obtained are comparable to archival literature values [28]. APT analyses are particularly useful for compositional analyses of nanometer length-scale precipitates [3, 20-21]. APT results (Table 1) of the $\theta^{\prime}$-precipitates exhibit evidence of significant partitioning of solutes; $\mathrm{Si}, \mathrm{Mg}$ and $\mathrm{Zn}$ to the $\theta^{\prime}$-precipitates for the three aging conditions. For example, the $\mathrm{Si}$ partitioning coefficient $\left(K_{s i} \theta^{\prime / \alpha-A l}\right)$ for $\theta^{\prime}$-precipitates for aging at $533 \mathrm{~K}$ is 4.9 . The Si partitioning

coefficient is $K_{S i}^{\theta^{\prime / \alpha}-A l}=\frac{c_{S i}^{\theta^{\prime}}}{c_{S i}^{\alpha-A l}}$, where $c_{S i}^{\theta^{\prime}}$ and $c_{S i}^{\alpha-A l}$ are the core concentrations of $\mathrm{Si}$ in the $\theta^{\prime}$ precipitate and $\alpha$-Al matrix, respectively. Similarly partitioning of $\mathrm{Si}$ to $\theta^{\prime}$-precipitates was observed in an Al-1.74 at. \% Cu alloy with a low-Si concentration, 3.8 for aging at $533 \mathrm{~K}$ [20]. We note that first- principles calculations for site occupancy in $\theta^{\prime}$-precipitates indicated that $\mathrm{Si}$ and $\mathrm{Zn}$ atoms prefer $\mathrm{Cu}$-sites, and $\mathrm{Mg}$ atoms prefer Al-sites [20-21]. With increasing aging temperature, the extent of solute partitioning decreases steadily, as expected, and after aging at $533 \mathrm{~K}$, the composition of the $\theta^{\prime}$-precipitates achieves its anticipated composition [11]. Similarly, APT analyses of the Q-phase precipitates present definitive evidence for partitioning of $\mathrm{Zn}$ to the Q-phase precipitates (Table 2), which diminishes rapidly with increasing aging temperature. Partitioning of $\mathrm{Zn}$ to the Q-phase precipitates is a kinetic effect as demonstrated by our firstprinciples calculations [3]. Again, aging at $533 \mathrm{~K}$ leads to the more commonly known Mg-rich composition for the Q-phase precipitates, which is similar to the composition of the bulk Qphase [3, 72]. Additionally, APT analyses have aided us in evaluating quantitatively the dimensions and number densities of the Q-phase precipitates. Effectively, important quantitative information on the evolution of $\theta^{\prime}$ - and Q-phase precipitates (Tables 1 and 2) have been determined successfully from TEM and APT analyses, which have enabled us to simulate SAXS profiles for different aging experiments. The most striking results of our SAXS experiments are 
the anisotropic scattered intensities from the precipitates [44-45], which are caused by: (i) the large grain size of the $\alpha$-Al-matrix ensuring effectively single-crystal SAXS patterns; and (ii) $\theta^{\prime}$ and Q-phase precipitates are both coherent and follow specific crystallographic orientation relationships with the $\alpha$-Al-matrix $[8,70]$. Similar anisotropic streaking is observed in case of a textured polycrystal, De Geuser et al. [46] in the case of $\theta^{\prime}$ - and $\mathrm{T}_{1}$ precipitates in an Al-Li-Cu alloy. Anisotropic scattered intensities necessitate simulations of SAXS profiles, which we performed using the necessary quantities from our TEM and APT results (Tables 1 and 2) and the crystallographic habit plane information [8, 70]. Figs. 5a-c and Figs. 6a-c explain and demonstrate the procedure. One particularly important point that emerges from this analysis is that the relative scattering length density of the $\theta^{\prime}$-precipitates is $\sim 40,000$ times greater than that of the Q-phase precipitates. This effectively makes the Q-phase precipitates invisible in the presence of $\theta^{\prime}$-precipitates, with respect to SAXS analyses. Therefore, our in situ SAXS analyses present the temporal evolution of the $\theta^{\prime}$-precipitates at three different aging temperatures. The thickness of the $\theta^{\prime}$-precipitates exhibit a sluggish rate of growth, whereas the growth of the radius is rapid (Fig. 9a), as we anticipated owing to the broad coherent faces that bound the $\theta^{\prime}$ platelets. This is in agreement with earlier studies of $\theta^{\prime}$-precipitates, both in Al-Cu binary alloys and in 319-type alloys [6-8]. The number density of $\theta^{\prime}$-precipitates displays a typical parabolic nature of temporal evolution, which implies that the precipitates are in the diffusion-limited growth regime, which precedes the growth and coarsening and stationary coarsening regimes (Fig. 10). We find that with increasing aging temperatures agreement with Lifshitz-SlyzovWagner (LSW) type coarsening models improves [73-78]. Specifically, the temporal exponent for $N_{v}$ for aging at $533 \mathrm{~K}$ is $-0.96 \pm 0.04$, which is in good agreement with the value of -1 dictated by LSW-type models. The temporal exponent for $\langle R(t)\rangle$ for the same aging condition isn't in agreement with the expected value of $1 / 3$. Importantly, we determined successfully the in situ temporal evolution of the dimensions and number densities of $\theta^{\prime}$-precipitates directly from SAXS experiments, which are easier to perform than the other techniques available for nanometer length-scale measurements. This technique can be implemented as a complementary method for monitoring age-hardening processes in commercial age-hardenable Al-alloys and Nibase superalloys in concert with TEM and APT.

\section{Conclusions}

We have performed a correlative study of the temporal evolution of nanometer lengthscale coherent precipitates in a commercial Al-alloy W319 at three different aging temperatures: 438, 463, and $533 \mathrm{~K}$, using small angle X-ray scattering (SAXS), TEM and atom-probe 
tomography (APT). Use of these three complementary techniques leads to the following significant points:

1. The APT analyses of $\mathrm{W} 319$ reveals clearly the compositional changes with increasing aging temperature for both the $\theta^{\prime}$ - and Q-phase precipitates, leading eventually to the anticipated compositions for each of them for aging at $533 \mathrm{~K}$. Both the $\theta^{\prime}$ - and Q-phase precipitates exhibit a significant amount of solute partitioning, which decreases with increasing aging temperature.

2. Anisotropic single-crystal SAXS intensities from these nanometer length-scale coherent precipitates have been successfully modeled using all the important physical parameters extracted from the TEM and APT analyses, which matches remarkably well the results of the ex situ SAXS experiments performed on aged samples of W319.

3. Single-crystal in situ SAXS analyses of W319 provide detailed quantitative information on the temporal evolution of the $\theta^{\prime}$-precipitates. With increasing aging temperatures, temporal exponents for the mean radius and number density of precipitates show greater agreement with Lifshitz-Slyzov-Wagner (LSW) type coarsening models. We have demonstrated an alternative technique for successfully extracting these parameters from anisotropic SAXS analyses in concert with TEM and APT experiments.

4. The methodology presented in this article, with correlative APT and TEM experiments, can also be utilized for age-hardening analyses of other commercial age-hardenable Al-based alloys and Ni-based super alloys.

\section{Acknowledgements:}

A.B. and D.N.S. acknowledge financial support from the Ford-Boeing-Northwestern Alliance. Atom-probe tomographic measurements were performed at the Northwestern University Center for Atom-probe tomography (NUCAPT). Funding for the purchase of the LEAP tomograph and for upgrades was provided by NSF-MRI (DMR 0420532), ONR-DURIP (N00014-0400798), and ONR-DURIP (N00014-0610539). The FEI dual-beam FIB is part of the EPIC facility at Northwestern, which is supported by NSF-NSEC, NSF-MRSEC, Keck Foundation, State of Illinois, and N.U. The authors would like to thank Dr. R. Tewari, B.A.R.C., Roger Alvis, Cameca, and Dr. Daniel Schreiber, Pacific Northwest National Laboratory, for their kind help. We also thank Drs. Donald S. Shih (Boeing), Krishnan K. Sankaran (formerly Boeing), Prof. John Allison (formerly Ford Research Laboratory and currently at University of Michigan at Ann Arbor), and James A. Coakley (Northwestern University and University of Cambridge). 


\section{References}

[1] J.G. Kaufman, Introduction to Aluminum Alloys and Tempers, ASM International, 2000.

[2] I.J. Polmear, Light Alloys: From Traditional Alloys to Nanocrystals, Elsevier Butterworth-Heinemann Ltd., 2006.

[3] A. Biswas, D.J. Siegel, D.N. Seidman, Compositional evolution of Q-phase precipitates in an aluminum alloy, Acta Mater. 75 (2014) 322-336.

[4] D. Apelian, Worldwide Report, Aluminum Cast Alloys: Enabling Tools for Improved Performance, NADCA, Wheeling, 2009.

[5] I. Dutta, C.P. Harper, G. Dutta, Role of $\mathrm{Al}_{2} \mathrm{O}_{3}$ particulate reinforcements on precipitation in 2014 Almatrix composites, Metall. Mater. Trans. 25A (1994) 1591-1602.

[6] H.I. Aaronson, C. Laird, Ford Motor Co. Scientific Laboratory Report No. SL 67-52, 1967.

[7] S.C. Weakley-Bolin, W. Donlon, C. Wolverton, J.W. Jones, J.E. Allison, Modeling the age-hardening behavior of Al-Si-Cu alloys, Metall. Mater. Trans. 35A (2004) 2407-2418.

[8] C. Laird, H.I. Aaronson, Structure and migration kinetics of alpha: theta prime boundaries in Al-4 pct $\mathrm{Cu}$ : part I-interfacial structures, Trans. Metall. Society of AIME 242 (1968) 1393-1403.

[9] H.I. Aaronson, J.B. Clark, C. Laird, Interfacial energy of dislocation and of coherent interphase boundaries, Metal Science J. 2 (1968) 155-158.

[10] V. Vaithyanathan, C. Wolverton, L.Q. Chen, Multiscale modeling of precipitate microstructure evolution, Phys. Rev. Lett. 88 (2002) 125503-1-4.

[11] V. Vaithyanathan, C. Wolverton, L.Q. Chen, Multiscale modeling of $\theta^{\prime}$ precipitation in Al-Cu binary alloys, Acta Mater. 52 (2004) 2973-2987.

[12] G.C. Weatherly, R.B. Nicholson, An electron microscope investigation of the interfacial structure of semi-coherent precipitates, Phil. Mag. 17 (1968) 801-831.

[13] J.D. Boyd, R.B. Nicholson, The coarsening behaviour of $\theta^{\prime \prime}$ and $\theta^{\prime}$ precipitates in two Al-Cu alloys, Acta Metall. 19 (1971) 1379-1391.

[14] R. Sankaran, C. Laird, Kinetics of growth of platelike precipitates, Acta Metall. 22 (1974) 957-969.

[15] U. Dahmen, K.H. Westmacott, Ledge structure and the mechanism of $\theta^{\prime}$ precipitate growth in Al-Cu, Phys. Stat. Sol. 80 (1983) 249-262.

[16] S.P. Ringer, K. Hono, T. Sakurai, Nucleation and growth of $\theta^{\prime}$ precipitation in Sn-modified Al-Cu alloys: APFIM/TEM observations, Appl. Surf. Sci. 87/88 (1995) 223-227.

[17] T. Honma, D.W. Saxey, S.P. Ringer, Effect of trace addition of Sn in Al-Cu alloy, Mater. Sci. For. 519521 (2006) 203-208.

[18] B.A. Shollock, C.R.M. Grovenor, K.M. Knowlcs, Compositional studies of $\Omega$ and $\theta^{\prime}$ precipitates in an AlCu-Mg-Ag Alloy, Scr. Metall. Mater. 24 (1990) 1239-1244. 
[19] N. Sano, K. Hono, T. Sakurai, K. Hirano, Atom-probe analysis of $\Omega$ and $\theta^{\prime}$ phases in an Al-Cu-Mg-Ag alloy, Scr. Metall. Mater. 25 (1991) 491-496.

[20] A. Biswas, D.J. Siegel, C. Wolverton, D.N. Seidman, Precipitates in Al-Cu alloys revisited: Atom-probe tomographic experiments and first-principles calculations of compositional evolution and interfacial segregation, Acta Mater. 59 (2011) 6187-6204.

[21] A. Biswas, D.J. Siegel, D.N. Seidman, Simultaneous segregation at coherent and semicoherent heterophase interfaces, Phys. Rev. Lett. 105 (2010) 076102-1-4.

[22] E.H. Dix, G.F. Sager, B.P. Sager, Equilibrium relations in $\mathrm{Al}-\mathrm{Cu}-\mathrm{Mg}$ and $\mathrm{Al}-\mathrm{Cu}-\mathrm{Mg}_{2} \mathrm{Si}$ of high purity, Trans. AIME 99 (1932) 119-131.

[23] G.C. Weatherly, A. Perovic, N.K. Mukhopadhyay, D.J. Lloyd, D.D. Perovic, The precipitation of the Q phase in an AA6111 alloy, Metall. Mater. Trans. 32A (2001) 213-218.

[24] L. Arnberg, B. Aurivillius, The crystal structure of $\mathrm{Al}_{\mathrm{x}} \mathrm{Cu}_{2} \mathrm{Mg}_{12-\mathrm{x}} \mathrm{Si}_{7}$, (h-AlCuMgSi), Acta Chem. Scand. A 34 (1980) 1-5.

[25] C. Wolverton, Crystal structure and stability of complex precipitate phases in $\mathrm{Al}-\mathrm{Cu}-\mathrm{Mg}-(\mathrm{Si})$ and $\mathrm{Al}-$ Zn-Mg alloys, Acta Mater. 49 (2001) 3129-3142.

[26] D.J. Chakrabarti, B. Cheong, D.E. Laughlin, Automotive Alloys II, S.K. Das, ed., TMS, Pittsburgh, PA, 1998, pp. 27-44.

[27] D.J. Chakrabarti, D.E. Laughlin, Phase relations and precipitation in $\mathrm{Al}-\mathrm{Mg}-\mathrm{Si}$ alloys with $\mathrm{Cu}$ additions, Prog. Mater. Sci. 49 (2004) 389-410.

[28] A. Perovic, D.D. Perovic, G.C. Weatherly, D.J. Lloyd, Precipitation in aluminum alloys AA6111 and AA6016, Scr. Mater. 41 (1999) 703-708.

[29] C. Cayron, L. Sagalowicz, O. Beffort, P.A. Buffat, Structural phase transition in Al-Cu-Mg-Si alloys by transmission electron microscopy study on an $\mathrm{Al}-4 \mathrm{wt} \% \mathrm{Cu}-1 \mathrm{wt} \% \mathrm{Mg}-\mathrm{Ag}$ alloy reinforced by $\mathrm{SiC}$ particles, Phil. Mag. A 79 (1999) 2833-2851.

[30] K. Matsuda, Y. Uetani, T. Sato, S. Ikeno, Metastable phases in an Al-Mg-Si alloy containing copper, Metall. Mater. Trans. 32A (2001) 1293-1299.

[31] K. Matsuda, D. Teguri, Y. Uetani, T. Sato, S. Ikeno, Cu-segregation at the Q'/ $\alpha-A 1$ interface in Al-MgSi-Cu alloy, Scr. Mater. 47 (2002) 833-837.

[32] J.Y. Hwang, R. Banerjee, H.W. Doty, M.J. Kaufman, The effect of Mg on the structure and properties of Type 319 aluminum casting alloys, Acta Mater. 57 (2009) 1308-1317.

[33] G. Groma, E. Kovács-csetényi, I. Kovács, J. Lendvai, T. Ungár, The composition of Guinier-Preston zones in Al-Zn-Mg alloys, Phil. Mag. A 40 (1979) 653-665.

[34] P. Guyot, L. Cottignies, Precipitation kinetics, mechanical strength and electrical conductivity of AlZnMgCu alloys, Acta Mater. 44 (1996) 4161-4167.

[35] A. Deschamps, F. Livet, Y. Bréchet, Influence of predeformation on ageing in an Al-Zn-Mg alloy - I. microstructure evolution and mechanical properties, Acta Mater. 47 (1999) 281-292. 
[36] C.S. Tsao, T.L. Lin, M.S. Yu, $\delta^{\prime}$ precipitation in Al-9.7at\%Li alloy using small-angle X-ray scattering, J. Alloys Comp. 289 (1999) 81-87.

[37] Z. Du, T. Zhou, P. Li, H. Li, B. Dong, C. Chen, Small angle x-ray scattering study of precipitation kinetics in Al-Zn-Mg-Cu Alloys, J. Mater. Sci. Technol. 21 (2005) 479-483.

[38] A. Guinier, The precipitation mechanism in a crystal of metallicsolid solution - the case of aluminum and aluminum-copper-silver systems, J. Phys. Radium 3 (1942) 124-136.

[39] A. Guinier, G. Fournet, Small-angle scattering of X-rays, John Wiley and Sons., New York, 1955.

[40] J.P. Simon, Contribution of synchrotron radiation to small-angle X-ray scattering studies in hard condensed matter, J. Appl. Cryst. 40 (2007) s1-s9.

[41] A. Deschamps, A. Bigot, F. Livet, P. Auger, Y. Bréchet, D. Blavette, A comparative study of precipitate composition and volume fraction in an $\mathrm{Al}-\mathrm{Zn}-\mathrm{Mg}$ alloy using tomographic atom probe and small-angle X-ray scattering, Phil. Mag. A 81 (2001) 2391-2414.

[42] P. Fratzl, Small-angle scattering in materials science - a short review of applications in alloys, ceramics and composite materials, J. Appl. Cryst. 36 (2003) 397-404.

[43] E. Clouet, L. La'e, T. Epicier, W. Lefebvre, M. Nastar, A. Deschamps, Complex precipitation pathways in multicomponent alloys, Nat. Mater. 5 (2006) 482-488.

[44] P. Fratzl, F.Langmayr, O. Paris, Evaluation of 3D small-angle scattering from non-spherical particles in single crystals, J. Appl. Cryst. 26 (1993) 820-826.

[45] O. Paris, M. Fahrmann, E. Fahrmann, T.M. Pollock, P. Fratzl, Early stages of precipitate rafting in a single crystal Ni-Al-Mo model alloy investigated by small-angle x-ray scattering and TEM, Acta Mater. 45 (1997) 1085-1097.

[46] F. De Geuser, F.Bley, A. Deschamps, A new method for evaluating the size of plate-like precipitates by small-angle scattering, J. Appl. Cryst. 45 (2012) 1208-1218.

[47] J.M. Boileau, J.E. Allison, The effect of solidification time and heat treatment on the fatigue properties of cast 319 alloy, Met. Mater. Trans. 34A (2003) 1807-1820.

[48] L.A. Giannuzzi, F.A. Stevie, Introduction to Focused Ion Beams. Kluwer, Academic Press, New York, 2004.

[49] L.A. Giannuzzi, P.A. Anzalone, R.J. Young, D.W. Phifer, Circumferential FIB milling for lift-out specimens, Microsc. Microanal. 12 (2006) 1310-1311.

[50] D. Lawrence, K. Thompson, D.J. Larson, Site-specific specimen preparation technique for atom probe analysis of grain boundaries, Microsc. Microanal. 12 (2006) 1740-1741.

[51] J.M. Cairney, D.W. Saxey, D. McGrouther, S.P. Ringer, Site-specific specimen preparation for atom probe tomography of grain boundaries, Physica B 394 (2007) 267-269.

[52] J. Takahashi, K. Kawakami, Y. Yamaguchi, M. Sugiyama, Development of atom probe specimen preparation techniques for specific regions in steel materials, Ultramicros. 107 (2007) 744-749. 
[53] K. Thompson, D. Lawrence, D.J. Larson, J.D. Olson, T.F. Kelly, B. Gorman, In situ site-specific specimen preparation for atom probe tomography, Ultramicros. 107 (2007) 131-139.

[54] F. Pérez-Willard, D. Wolde-Giorgis, T. Al-Kassab, G.A. López, E.J. Mittemeijer, R. Kirchheim, D. Gerthsen, Focused ion beam preparation of atom probe specimens containing a single crystallographically well-defined grain boundary, Micron 39 (2008) 45-52.

[55] T.F. Kelly, P.P. Camus, D.J. Larson, L.M. Holzman, S.S. Bajikar, On the many advantages of localelectrode atom probes, Ultramicros. 62 (1996) 29-42.

[56] T.F. Kelly, D.J. Larson, Local electrode atom probes, Mater. Charac. 44 (2000) 59-85.

[57] T.F. Kelly, T.T. Gribb, J.D. Olson, R.L. Martens, J.D. Shepard, S.A. Wiener, T.C. Kunicki, R.M. Ulfig, D.R. Lenz, E.M. Strennen, E. Oltman, J.H. Bunton, D.R. Strait, First data from a commercial local electrode atom probe (LEAP), Microsc. Microanal. 10 (2004) 373-383.

[58] T.F. Kelly, D.J. Larson, K. Thompson, R.L. Alvis, J.H. Bunton, J.D. Olson, B.P. Gorman, Atom probe tomography of electronic materials, Ann. Rev. Mater. Res. 37 (2007) 681-727.

[59] T.F. Kelly, M.K. Miller, Invited review article: atom probe tomography, Rev. Sci. Instru.78 (2007) 031101-1-20.

[60] D.N. Seidman, Three-dimensional atom-probe tomography: advances and applications, Ann. Rev. Mater. Res. 37 (2007) 127-158.

[61] O.C. Hellman, J.B. du Rivage, D.N. Seidman, Efficient sampling for three-dimensional atom probe microscopy data, Ultramicros. 95 (2003) 199-205.

[62] O.C. Hellman, J.A. Vandenbroucke, J. Rüsing, D. Isheim, D.N. Seidman, Analysis of three-dimensional atom-probe data by the proximity histogram, Microsc. Microanal. 6 (2000) 437-444.

[63] C.B. Fuller, J.L. Murray, D.N. Seidman, Temporal evolution of the nanostructure of Al(Sc,Zr) alloys: Part I-chemical compositions of $\mathrm{Al}_{3}\left(\mathrm{Sc}_{1-\mathrm{x}} \mathrm{Zr}_{\mathrm{x}}\right)$ precipitates, Acta Mater. 53 (2005) 5401-5413.

[64] E.A. Marquis, D.N. Seidman, M. Asta, C. Woodward, Composition evolution of nanoscale $\mathrm{Al}_{3} \mathrm{Sc}$ precipitates in an Al-Mg-Sc alloy: experiments and computations, Acta Mater. 54 (2006) 119-130.

[65] D. Isheim, M.S. Gagliano, M.E. Fine, D.N. Seidman, Interfacial segregationat Cu-richprecipitates in a high-strengthlow-carbon steel studied on a sub-nanometer scale, Acta Mater. 54 (2006) 841-849.

[66] E.A. Marquis, D.N. Seidman, M. Asta, C.Woodward, V. Ozoliņš, Mg segregation at $\mathrm{Al} / \mathrm{Al}_{3} \mathrm{Sc}$ heterophase interfaces on an atomic scale: experiments and computations, Phys. Rev. Lett. 91 (2003) 036101-1-4.

[67] E.A. Marquis, Ph.D. thesis, Northwestern University, 2002.

[68] E.A. Marquis, D.N. Seidman, Nanostructural evolution of $\mathrm{Al}_{3} \mathrm{Sc}$ precipitates in an $\mathrm{Al}-\mathrm{Sc}-\mathrm{Mg}$ alloy by three-dimensional atom probe microscopy, Surf. Inter. Anal. 36 (2004) 559-563.

[69] M.J. Caton, J.W. Jones, J.E. Allison, Use of small fatigue crack growth analysis in predicting the S-N response of cast aluminum alloys, ASTM STP 1372, J.C. Newman, Jr., R.S. Piascik, eds., West Conshohocken, PA, 2000. 
[70] L. Sagalowicz, G. Lapasset, G. Hug, Transmission electron microscopy study of a precipitate which forms in the Al-Mg-Si system, Phil. Mag. Lett. 74 (1996) 57-66.

[71] C.L. Chiang. Statistical methods of analysis, World Scientific, River Edge, N.J., 2003.

[72] G. Phragmen, On the phases occupying in alloys of aluminum with copper, magnesium, manganese, iron, and silicon, J. Inst. Metals 77 (1950) 489-552.

[73] I.M. Lifshitz, V.V. Slyozov. The kinetics of precipitation from supersaturated solid solutions, J. Phys. Chem. Solids 19 (1961) 35-50.

[74] C. Wagner. Theorie der alterung von niederschlagen durch umlosen (Ostwald-reifung), Z. Elektrochem. 65 (1961) 581-591.

[75] A. Umantsev, G.B. Olson, Ostwald ripening in multicomponent alloys, Scr. Metall. Mater. 29 (1993) 1135-1140.

[76] J.E. Morral, G.R. Purdy, Particle coarsening in binary and multicomponent alloys, Scr. Metall. Mater. 30 (1994) 905-908.

[77] C.J. Kuehmann, P.W. Voorhees, Ostwald ripening in ternary alloys, Metall. Mater. Trans. A 27A (1996) 937-943.

[78] T. Philippe, P.W. Voorhees, Ostwald ripening in multicomponent alloys, Acta Mater. 64 (2013) 42374244. 


\section{Figure Captions}

Figure 1. Transmission electron microscope micrographs depicting Q-phase and $\theta^{\prime}$-precipitates for the $\langle 100\rangle_{\alpha-A l}$ zone axis: (a) and (b) are representative bright-field TEM micrographs, after aging at $438 \mathrm{~K}$ for $8 \mathrm{~h}$ and at $533 \mathrm{~K}$ for $4 \mathrm{~h}$, respectively. The inset in (a) shows a magnified view of the precipitates marked by arrows and the corresponding diffraction pattern is given in an inset in (b).

Figure 2. 3D atom-probe tomographic reconstructions of a sample of W319: (a) and (b) are after aging at $438 \mathrm{~K}$ for $8 \mathrm{~h}$; (c) after aging at $533 \mathrm{~K}$ for $4 \mathrm{~h}$. Aluminum, $\mathrm{Cu}$ and $\mathrm{Mg}$ atoms are displayed in blue, red and green, respectively in (a); (b) displays a selected portion from the same dataset, where the isoconcentration surfaces are created with respect to $\mathrm{Mg}$ and $\mathrm{Cu}$, delineating both Q-phase and $\theta^{\prime}$-precipitates; (c) $\mathrm{Cu}$-isoconcentration surface delineates a large $\theta^{\prime}$-precipitate in the sample aged at $533 \mathrm{~K}$ for $4 \mathrm{~h}$.

Figure 3. Proximity histogram for a sample aged at $533 \mathrm{~K}$ for $4 \mathrm{~h}$. The solid vertical line indicates the location of the heterophase interface between the $\alpha$-Al matrix and the $\theta^{\prime}$-precipitates, which is, by definition, at the inflection point of the Al concentration profile. The spatial concentration profiles for the $\theta^{\prime}$-precipitates and $\alpha$-Al matrix are displayed on the right- and lefthand sides of this vertical line, respectively.

Figure 4. (a) to (c) show the experimentally obtained ex situ SAXS patterns, corresponding to the following three aging conditions: (a) $438 \mathrm{~K}$ for $8 \mathrm{~h}$; (b) $463 \mathrm{~K}$ for $8 \mathrm{~h}$; and (c) $533 \mathrm{~K}$ for $4 \mathrm{~h}$. The large grain size of the $\alpha$-Al matrix of W319 ensures effectively single-crystalline scattering intensity. As a result, characteristic anisotropic streaking is observed in each pattern.

Figure 5. (a) to (c) show the simulated 2D small-angle X-ray scattering pattern corresponding to aging at $463 \mathrm{~K}$ for $8 \mathrm{~h}$ for the following three cases: (a) four variants of Q-phase precipitates considered independently; (b) two variants of $\theta^{\prime}$-precipitates considered independently; and (c) a combination of four variants of the Q-phase and two variants of $\theta^{\prime}$-precipitates.

Figure 6. An off-plane tilt angle of $8^{0}$ accounts successfully for the unequal streak lengths, as illustrated in (a) to (c) corresponding to (a) the ex situ SAXS analysis of a sample aged at $463 \mathrm{~K}$ for $8 \mathrm{~h}$; (b) the experimental and the simulated results, respectively; and (c) displays the overlap of one-on-top-of-the-other. The contour map in (c) confirms that the simulated image matches the experimental results fairly well.

Figure 7. Temporal evolution of small-angle X-ray scattering intensity corresponding to in situ SAXS analysis of W319 at $463 \mathrm{~K}$.

Figure 8. Typical comparison of the intensity variation along a streak between the experimental and simulated pattern, for a specimen aged in situ for $8 \mathrm{~h}$ at $463 \mathrm{~K}$.

Figure 9. (a) and (b) display the temporal variation of the thickness and radius of the $\theta^{\prime}$ precipitates, respectively, for all the samples aged at 438 (up to $24 \mathrm{~h}$ ), 463 (up to $8 \mathrm{~h}$ ) and $533 \mathrm{~K}$ (up to $4.67 \mathrm{~h}$ ). Temporal exponents for the radius are determined using multivariate nonlinear regression analyses and are displayed in (b). 
Figure 10. The variation of number density is plotted, comparing the aging response of the following two aging temperatures as a function of aging time: 463 and $533 \mathrm{~K}$. Temporal exponents for the number density are determined using multivariate nonlinear regression analyses and are displayed in the figure.

\section{$\underline{\text { Table Captions }}$}

Table 1. Changes in dimensions and number density of the $\theta^{\prime}$-precipitates and its concomitant compositional evolution with increasing aging temperatures.

Table 2. Changes in dimensions and number density of the Q-phase precipitates and its concomitant compositional evolution with increasing aging temperatures.

Table 3. Detailed crystallographic and dimensional information corresponding to the simulation presented in Fig. 5. Comparative scattering length densities and the resultant scaling factors for the Q-phase and $\theta^{\prime}$-precipitates are also listed. 
Fig. 1
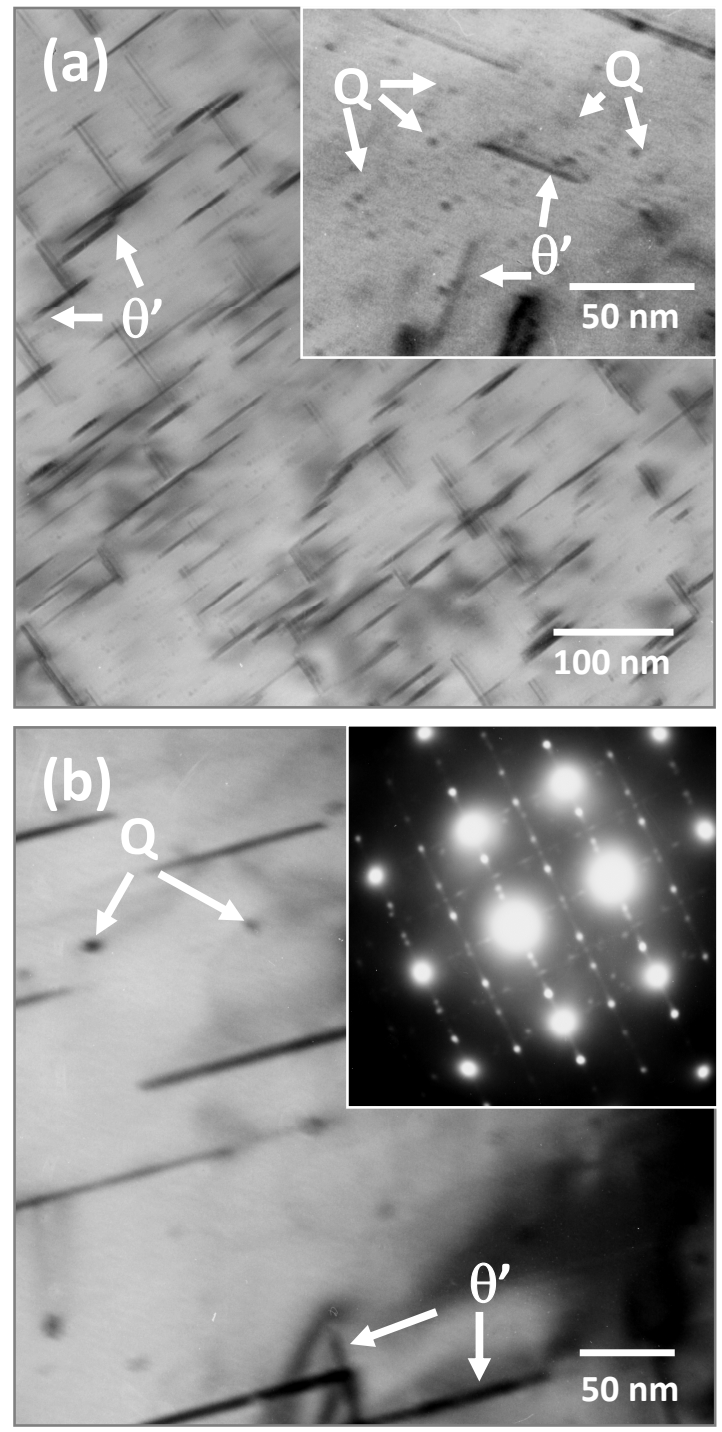

Figure 1. Transmission electron microscope micrographs depicting Q-phase and $\theta^{\prime}$-precipitates for the $\langle 100\rangle_{\alpha-\mathrm{Al}}$ zone axis: (a) and (b) are representative bright-field TEM micrographs, after aging at $438 \mathrm{~K}$ for $8 \mathrm{~h}$ and at $533 \mathrm{~K}$ for $4 \mathrm{~h}$, respectively. The inset in (a) shows a magnified view of the precipitates marked by arrows and the corresponding diffraction pattern is given in an inset in (b). 
Fig. 2
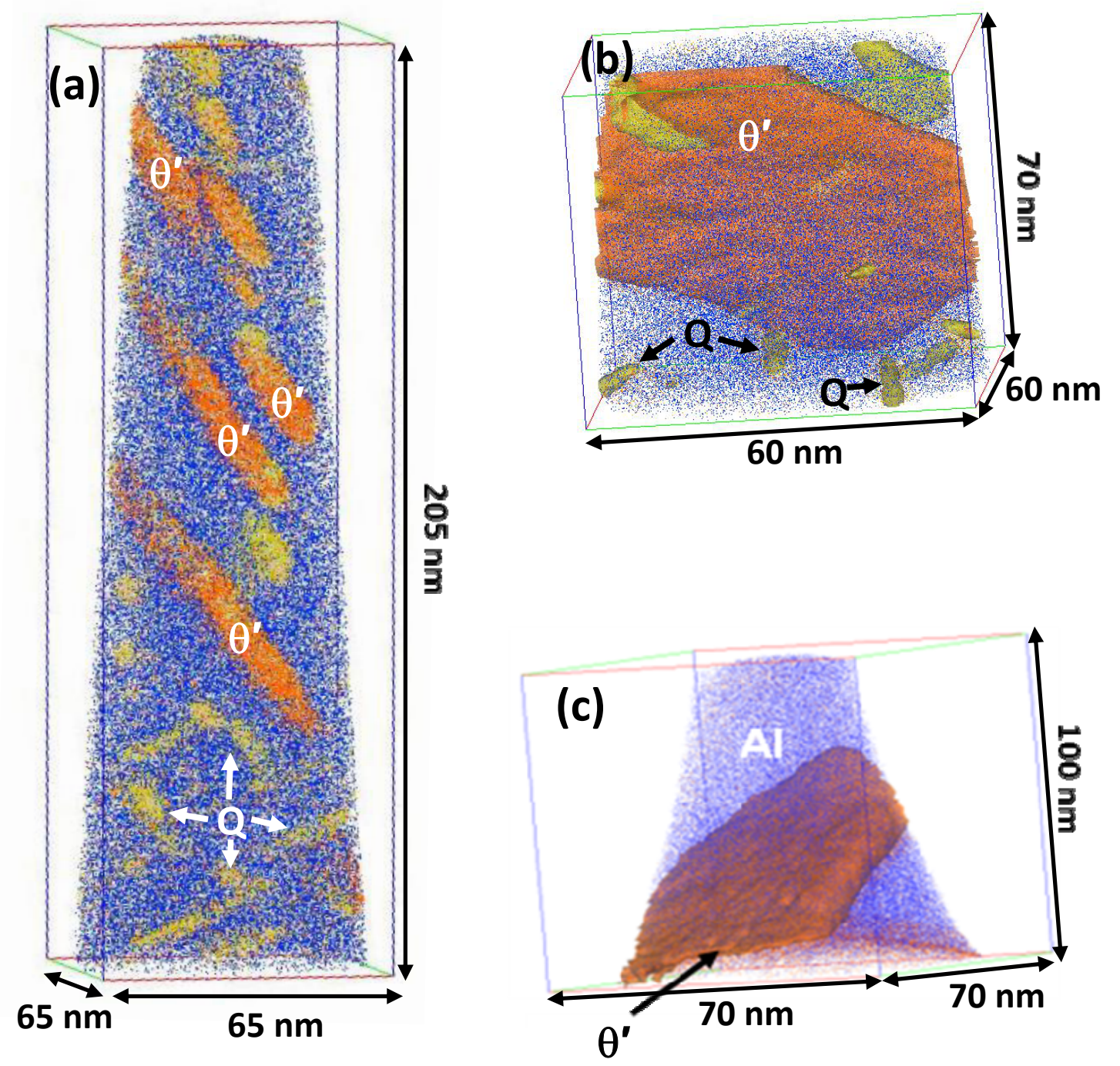

Figure 2. 3D atom-probe tomographic reconstructions of a sample of W319: (a) and (b) are after aging at $438 \mathrm{~K}$ for $8 \mathrm{~h}$; (c) after aging at $533 \mathrm{~K}$ for $4 \mathrm{~h}$. Aluminum, $\mathrm{Cu}$ and $\mathrm{Mg}$ atoms are displayed in blue, red and green, respectively in (a); (b) displays a selected portion from the same dataset, where the isoconcentration surfaces are created with respect to $\mathrm{Mg}$ and $\mathrm{Cu}$, delineating both Q-phase and $\theta^{\prime}$-precipitates; (c) $\mathrm{Cu}$ isoconcentration surface delineates a large $\theta^{\prime}$-precipitate in the sample aged at $533 \mathrm{~K}$ for $4 \mathrm{~h}$. 
Fig. 3

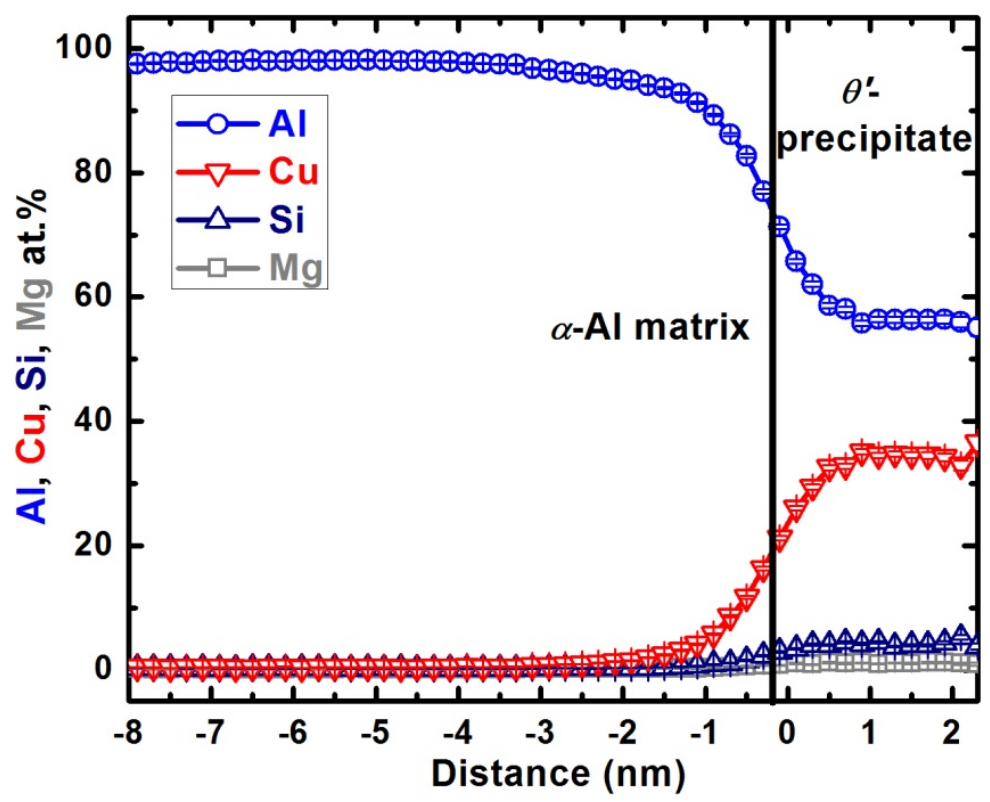

Figure 3. Proximity histogram for a sample aged at $533 \mathrm{~K}$ for $4 \mathrm{~h}$. The solid vertical line indicates the location of the heterophase interface between the $\alpha$-Al matrix and the $\theta^{\prime}$ precipitates, which is, by definition, at the inflection point of the $\mathrm{Al}$ concentration profile. The spatial concentration profiles for the $\theta^{\prime}$-precipitates and $\alpha$-Al matrix are displayed on the right- and left-hand sides of this vertical line, respectively. 
Fig. 4
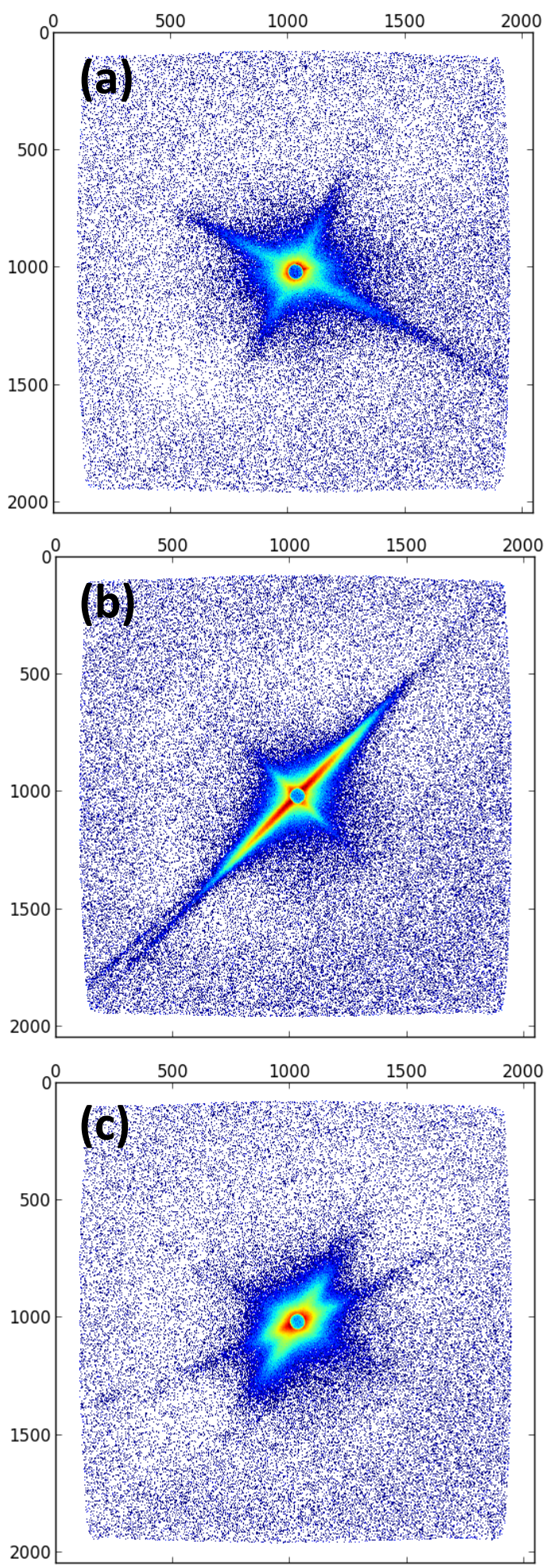

Figure 4. (a) to (c) show the experimentally obtained ex situ SAXS patterns, corresponding to the following three aging conditions: (a) $438 \mathrm{~K}$ for $8 \mathrm{~h}$; (b) $463 \mathrm{~K}$ for $8 \mathrm{~h}$; and (c) $533 \mathrm{~K}$ for $4 \mathrm{~h}$. The large grain size of the $\alpha$-Al matrix of W319 ensures effectively single-crystalline scattering intensity. As a result, characteristic anisotropic streaking is observed in each pattern. 
Fig. 5
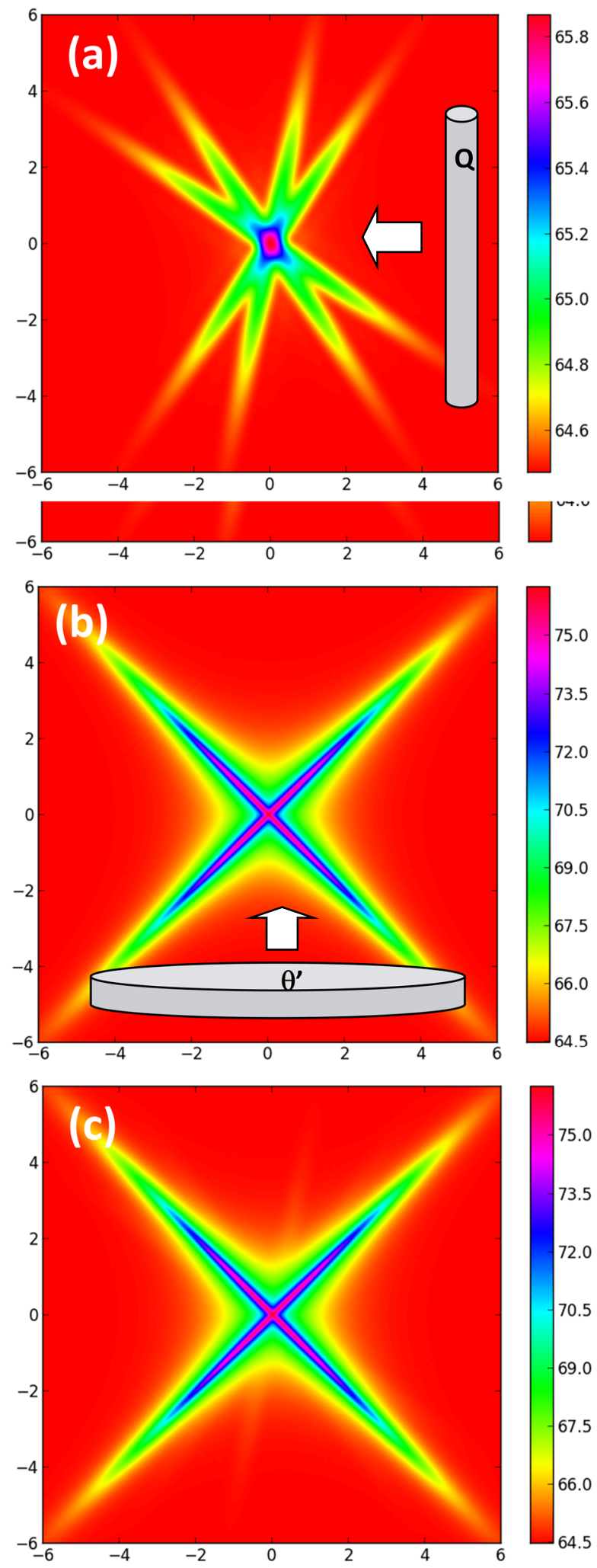

Figure 5. (a) to (c) show the simulated 2D small-angle X-ray scattering pattern corresponding to aging at $463 \mathrm{~K}$ for $8 \mathrm{~h}$ for the following three cases: (a) four variants of Q-phase precipitates considered independently; (b) two variants of $\theta^{\prime}$ precipitates considered independently; and (c) a combination of four variants of the Q-phase and two variants of $\theta^{\prime}$ precipitates. 
Fig. 6
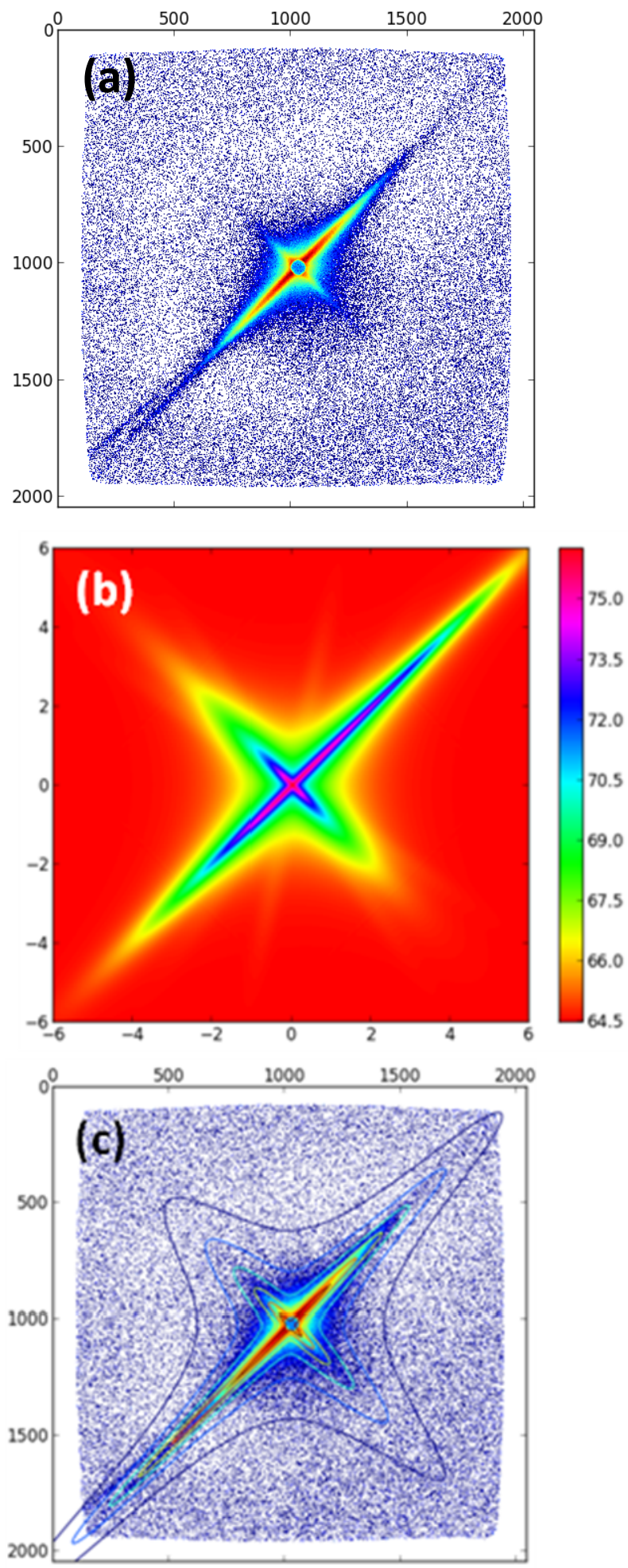

Figure 6. An off-plane tilt angle of $8^{0}$ accounts successfully for the unequal streak lengths, as illustrated in (a) to (c) corresponding to (a) the ex situ SAXS analysis of a sample aged at $463 \mathrm{~K}$ for $8 \mathrm{~h}$; (b) the experimental and the simulated results, respectively; and (c) displays the overlap of one-on-top-of-the-other. The contour map in (c) confirms that the simulated image matches the experimental results fairly well. 
Fig. 7
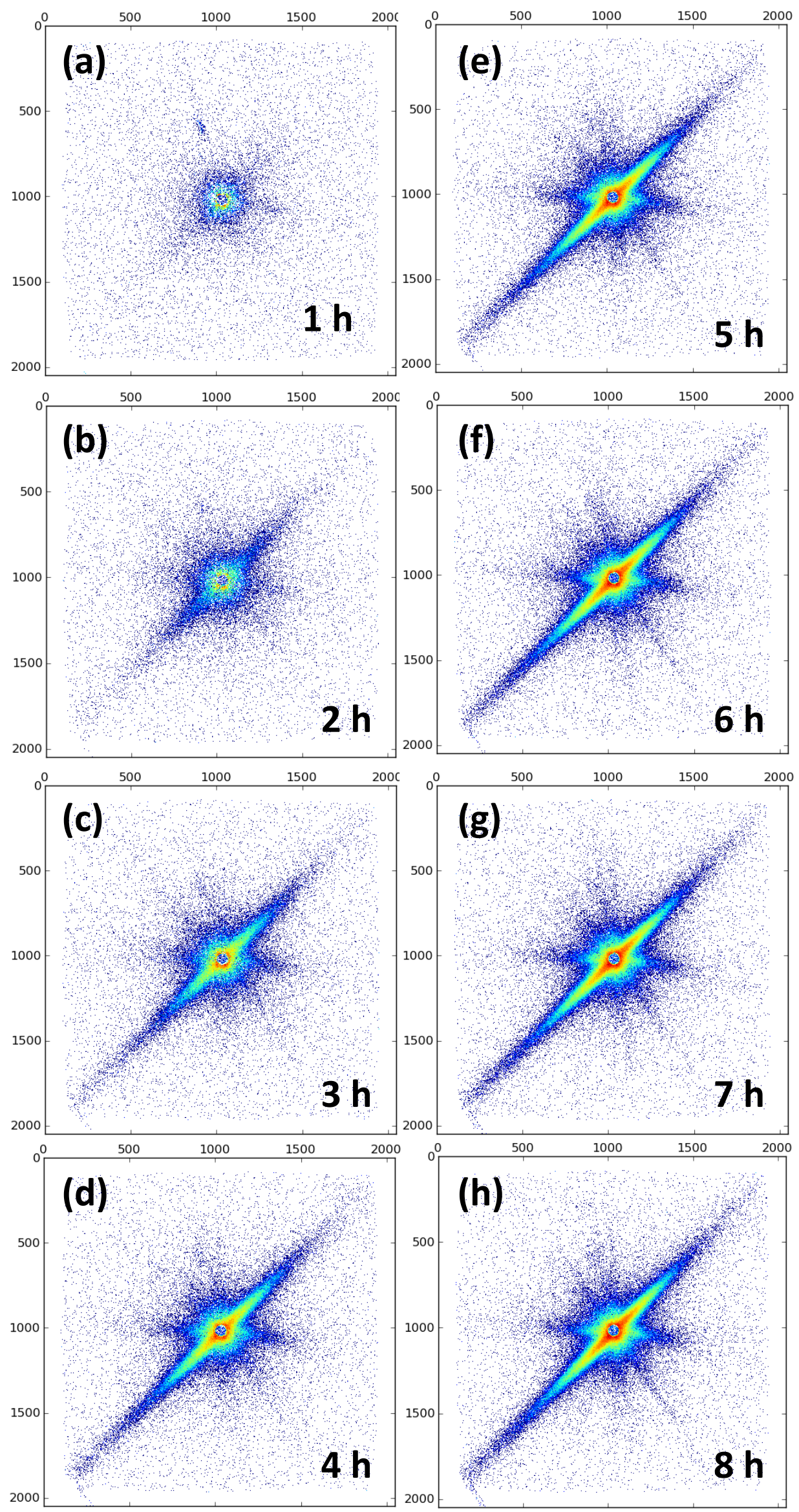

(g)

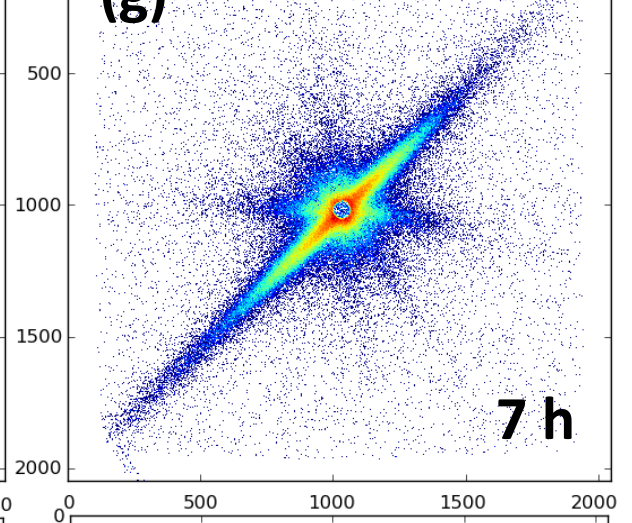

(h)

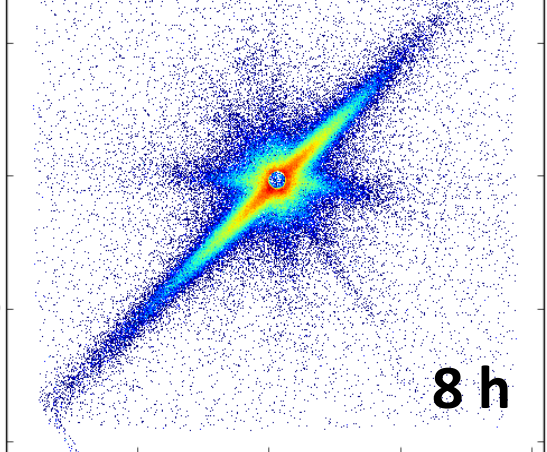

Figure 7. Temporal evolution of small-angle X-ray scattering intensity corresponding to in situ SAXS analysis of W319 at $463 \mathrm{~K}$. 
Fig. 8

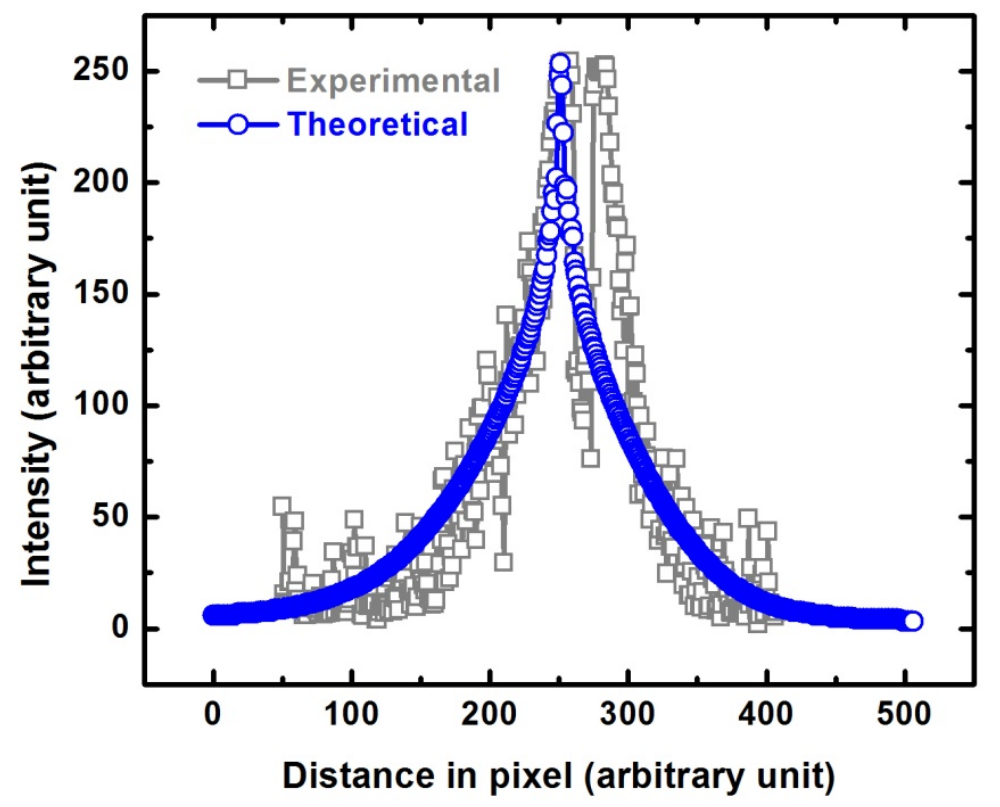

Figure 8. Typical comparison of the intensity variation along a streak between the experimental and simulated pattern, for a specimen aged in situ for $8 \mathrm{~h}$ at $463 \mathrm{~K}$. 
Fig. 9
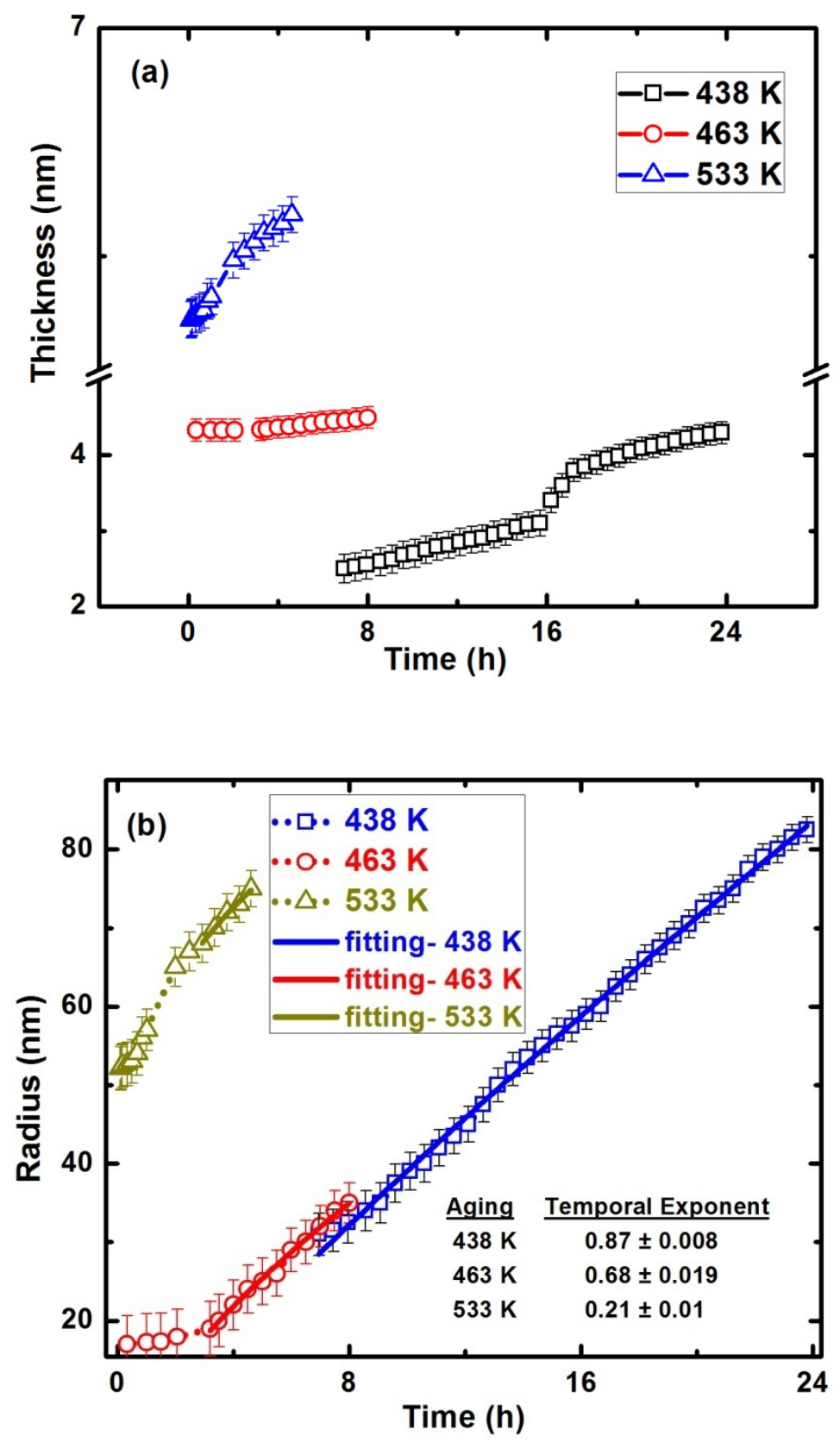

Figure 9. (a) and (b) display the temporal variation of the thickness and radius of the $\theta^{\prime}$-precipitates, respectively, for all the samples aged at 438 (up to $24 \mathrm{~h}$ ), 463 (up to $8 \mathrm{~h}$ ) and $533 \mathrm{~K}$ (up to $4.67 \mathrm{~h}$ ). Temporal exponents for the radius are determined using multivariate nonlinear regression analyses and are displayed in (b). 
Fig. 10

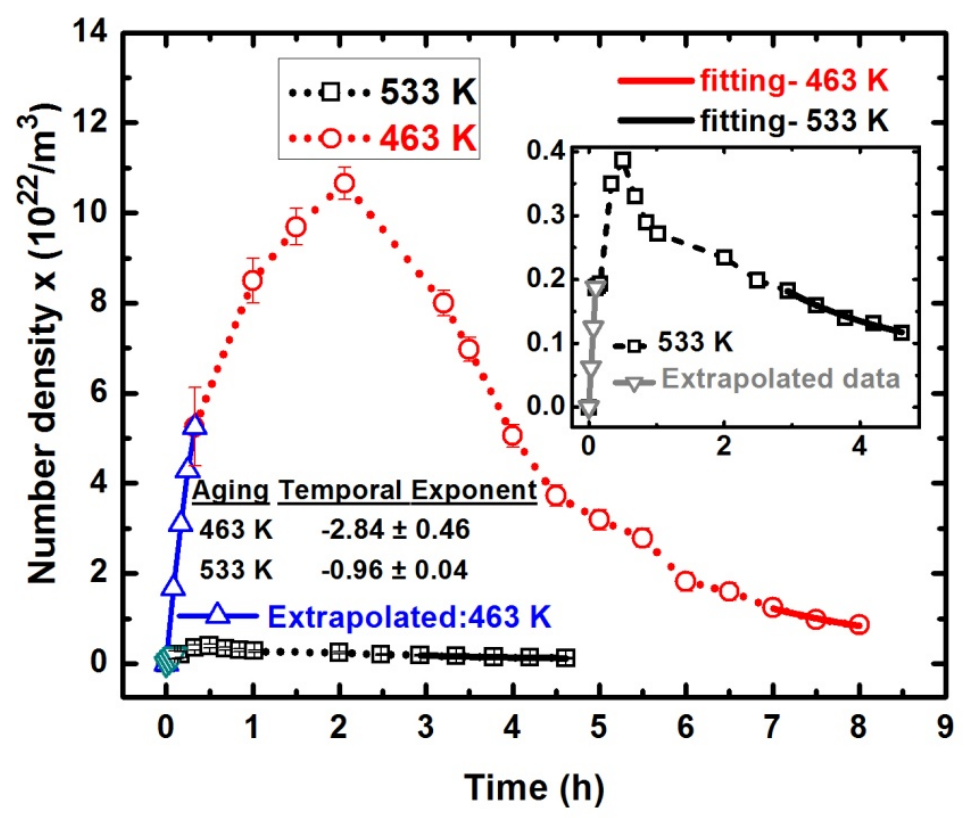

Figure 10. The variation of number density is plotted, comparing the aging response of the following two aging temperatures as a function of aging time: 463 and $533 \mathrm{~K}$. Temporal exponents for the number density are determined using multivariate nonlinear regression analyses and are displayed in the figure. 
Table 1. Changes in dimensions and number density of the $\theta^{\prime}$-precipitates and its concomitant compositional evolution with increasing aging temperatures.

\begin{tabular}{|c|c|c|c|}
\hline$\theta^{\prime}$-phase (plate) & $438 \mathrm{~K}-8 \mathrm{~h}$ & $463 \mathrm{~K}-8 \mathrm{~h}$ & $533 \mathrm{~K}-4 \mathrm{~h}$ \\
\hline Diameter (nm) & $60 \pm 2.1$ & $70 \pm 3.7$ & $110 \pm 6.3$ \\
\hline $\begin{array}{l}\text { Thickness }(\mathrm{nm}) \\
\text { Number density } \\
\left(\text { precipitate } / \mathrm{m}^{3}\right)\end{array}$ & $\begin{array}{c}2.5 \pm 0.1 \\
1.12 \pm 0.2 \times 10^{22}\end{array}$ & $\begin{array}{c}4.5 \pm 0.17 \\
0.86 \pm 0.1 \times 10^{22}\end{array}$ & $\begin{array}{c}6.5 \pm 0.24 \\
1.4 \pm 0.2 \times 10^{21}\end{array}$ \\
\hline $\mathrm{Al}($ at. \%) & $57.88 \pm 3.16$ & $58.62 \pm 1.1$ & $66.98 \pm 0.8$ \\
\hline $\mathrm{Cu}($ at. \%) & $35.28 \pm 3.46$ & $37.2 \pm 1.2$ & $31.36 \pm 0.79$ \\
\hline Si (at. \%) & $4.29 \pm 1.33$ & $2.44 \pm 0.33$ & $1.50 \pm 0.19$ \\
\hline Mg (at. \%) & $1.265 \pm 0.4$ & $1.23 \pm 0.27$ & $0.11 \pm 0.05$ \\
\hline Zn (at. \%) & $1.52 \pm 0.65$ & $0.42 \pm 0.08$ & $0.09 \pm 0.04$ \\
\hline
\end{tabular}


Table 2. Changes in dimensions and number density of the Q-phase precipitates and its concomitant compositional evolution with increasing aging temperatures.

\begin{tabular}{|c|c|c|c|}
\hline Q-phase (rod) & $438 \mathrm{~K}-8 \mathrm{~h}$ & $463 \mathrm{~K}-8 \mathrm{~h}$ & $533 \mathrm{~K}-4 \mathrm{~h}$ \\
\hline Diameter (nm) & $2.1 \pm 0.1$ & $2.03 \pm 0.27$ & $9.45 \pm 0.94$ \\
\hline $\begin{array}{l}\text { Length (nm) } \\
\text { Number density } \\
\left(\text { precipitate } / \mathrm{m}^{3} \text { ) }\right.\end{array}$ & $\begin{array}{c}20.02 \pm 1.5 \\
8.1 \pm 0.1 \times 10^{22}\end{array}$ & $\begin{array}{c}25.01 \pm 1.47 \\
5.01 \pm 0.2 \times 10^{22}\end{array}$ & $\begin{array}{c}75.63 \pm 1.24 \\
5.37 \pm 0.4 \times 10^{21}\end{array}$ \\
\hline $\mathrm{Al}($ at. \%) & $44.23 \pm 5.2$ & $44.07 \pm 4.3$ & $27.74 \pm 1.94$ \\
\hline $\mathrm{Cu}($ at. \%) & $22.56 \pm 1.74$ & $22.0 \pm 3.2$ & $9.23 \pm 1.24$ \\
\hline $\operatorname{Mg}($ at. $\%)$ & $14.89 \pm 2.87$ & $17.4 \pm 1.9$ & $36.84 \pm 2.08$ \\
\hline Si (at. \%) & $17.12 \pm 1.14$ & $15.8 \pm 1.45$ & $26.17 \pm 1.89$ \\
\hline $\mathrm{Zn}($ at. \%) & $1.08 \pm 0.44$ & $0.73 \pm 0.15$ & $0.074 \pm 0.05$ \\
\hline
\end{tabular}


Table 3. Detailed crystallographic and dimensional information corresponding to the simulation presented in Fig. 5. Comparative scattering length densities and the resultant scaling factors for the Q-phase and $\theta^{\prime}$ precipitates are also listed.

\begin{tabular}{|c|c|c|c|c|c|c|}
\hline Variant & Q-1 & Q-2 & Q-3 & Q-4 & $\theta^{\prime}-1$ & $\theta^{\prime}-2$ \\
\hline Angle (degree) & 0.0 & 22.62 & 67.38 & 90.0 & 11.31 & 101.31 \\
\hline \multicolumn{7}{|c|}{ Data corresponding to aging at $463 \mathrm{~K}$ for $8 \mathrm{~h}$} \\
\hline Diameter (nm) & \multicolumn{4}{|c|}{$2.03 \pm 0.27$} & \multicolumn{2}{|c|}{$70 \pm 3.7$} \\
\hline Length (nm)/Thickness (nm) & \multicolumn{4}{|c|}{$25.01 \pm 1.47$} & \multicolumn{2}{|c|}{$4.5 \pm 0.17$} \\
\hline Density (g/cc) & \multicolumn{4}{|c|}{2.7671} & \multicolumn{2}{|c|}{6.3521} \\
\hline$N_{v}=$ Number density $\left(\mathrm{m}^{-3}\right)$ & \multicolumn{4}{|c|}{$5.01 \pm 0.2 \times 10^{22}$} & \multicolumn{2}{|c|}{$0.86 \pm 0.1 \times 10^{22}$} \\
\hline$V=$ Volume $^{2}\left(\mathrm{~m}^{6}\right)$ & \multicolumn{4}{|c|}{$6.545 \times 10^{-51}$} & \multicolumn{2}{|c|}{$2.996 \times 10^{-46}$} \\
\hline$\rho=$ Scattering length density $\left(\mathrm{cm}^{-2}\right)$ & \multicolumn{4}{|c|}{$2.278 \times 10^{11}$} & \multicolumn{2}{|c|}{$5.049 \times 10^{11}$} \\
\hline Scaling factor & \multicolumn{4}{|c|}{17.016} & \multicolumn{2}{|c|}{656827} \\
\hline
\end{tabular}



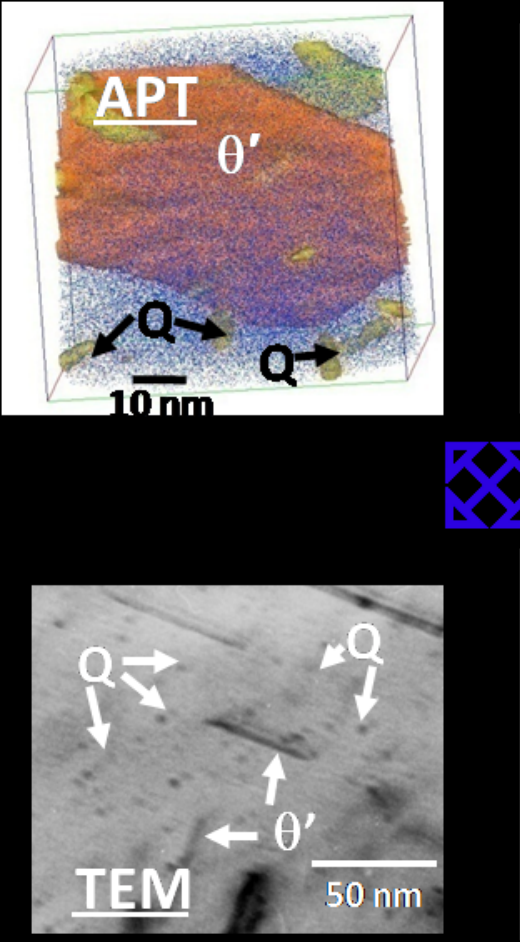

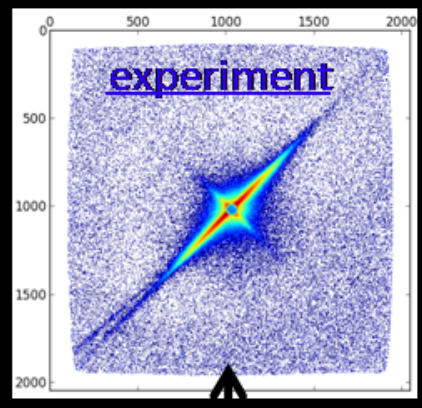

500

1000

1500

2000

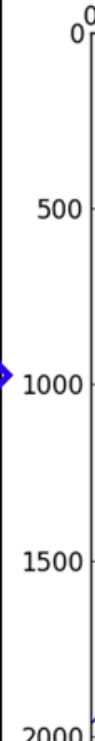

vallation

it:

W.

19.

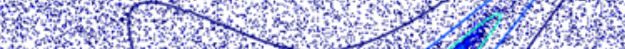

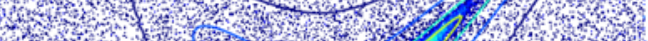

ar $x$.

W.

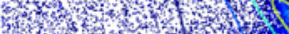

W.

a

atim, $\sin x+x^{2}$ 30.7 .

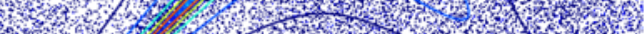

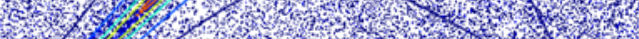

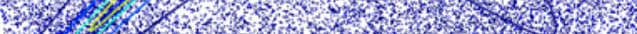

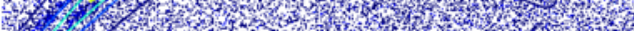

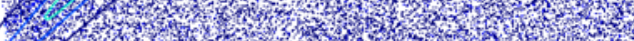
2000 